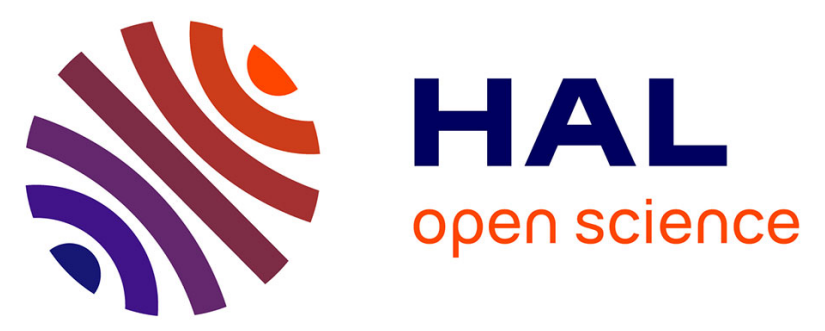

\title{
Loss of floor plate Netrin-1 impairs midline crossing of corticospinal axons and leads to mirror movements
}

Nadège Sarrazin, Fabio Marti, Nicolas Heck, Cecile Gallea, Mohamed

Doulazmi, Sergi Roig Puiggros, Juan Antonio Moreno-Bravo, Marie Vidailhet, Alain Trembleau, Philippe Faure, et al.

\section{To cite this version:}

Nadège Sarrazin, Fabio Marti, Nicolas Heck, Cecile Gallea, Mohamed Doulazmi, et al.. Loss of floor plate Netrin-1 impairs midline crossing of corticospinal axons and leads to mirror movements. Cell Reports, 2021, 34 (3), pp.108654. 10.1016/j.celrep.2020.108654 . hal-03145091

\section{HAL Id: hal-03145091 \\ https://hal.sorbonne-universite.fr/hal-03145091}

Submitted on 18 Feb 2021

HAL is a multi-disciplinary open access archive for the deposit and dissemination of scientific research documents, whether they are published or not. The documents may come from teaching and research institutions in France or abroad, or from public or private research centers.
L'archive ouverte pluridisciplinaire HAL, est destinée au dépôt et à la diffusion de documents scientifiques de niveau recherche, publiés ou non, émanant des établissements d'enseignement et de recherche français ou étrangers, des laboratoires publics ou privés. 


\section{Cell Reports}

\section{Loss of floor plate Netrin-1 impairs midline crossing of corticospinal axons and leads to mirror movements}

\section{Graphical Abstract}

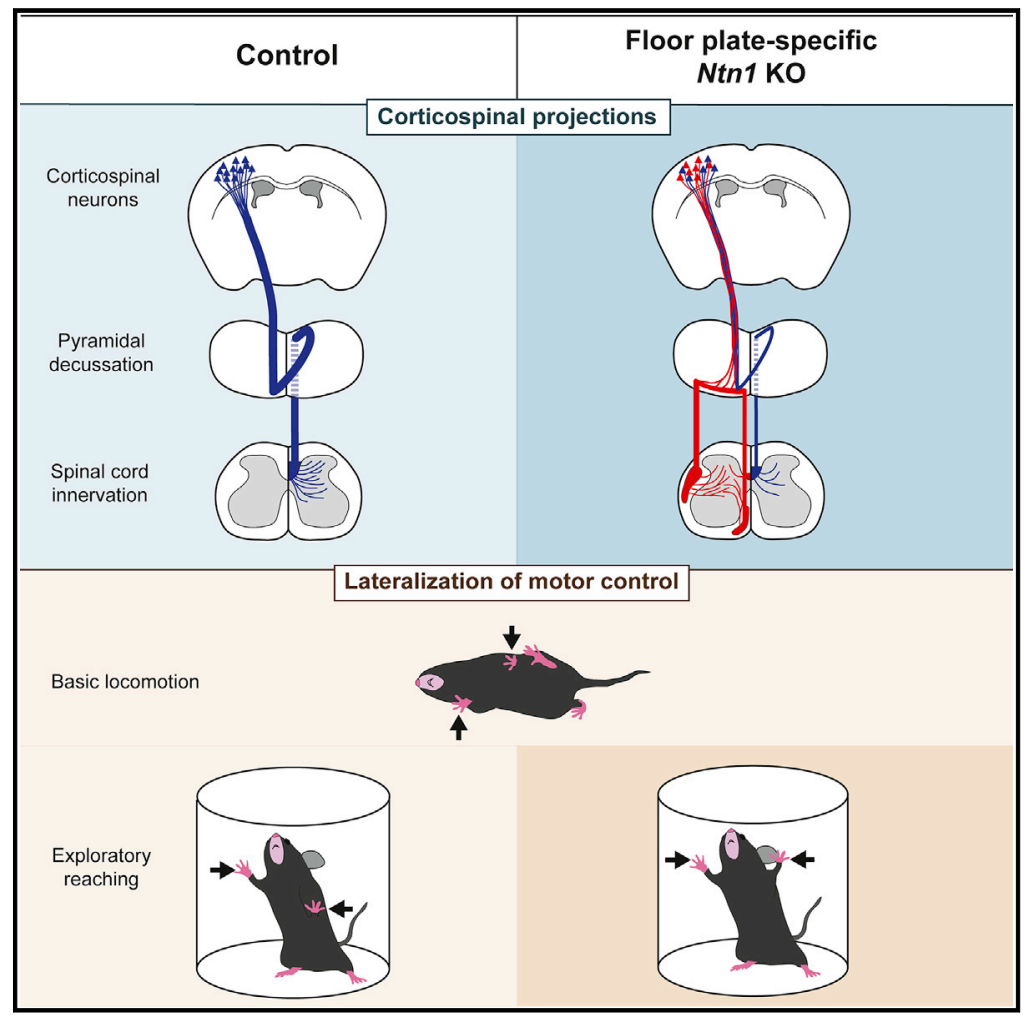

\section{Highlights}

- Depletion of floor plate Netrin-1 impairs midline crossing of corticospinal axons

- Shh::cre;Ntn $1^{\text {lox/lox }}$ mice have functional ipsilateral corticospinal projections

- Lateralization of voluntary motor controls is selectively altered in these mice

- These mice represent a model for human congenital mirror movements

\section{Authors}

Oriane Pourchet, Marie-Pierre Morel, Quentin Welniarz, ..., Alain Chédotal, Emmanuel Roze, Isabelle Dusart

\section{Correspondence}

isabelle.dusart@upmc.fr

\section{In Brief}

Pourchet et al. show that depletion of floor plate Netrin-1 disrupts the guidance of corticospinal axons at the pyramidal decussation and leads to abnormal ipsilateral projections. This anatomical defect impairs lateralization of voluntary, but not automatic, movements, similar to what is observed in patients with congenital mirror movements. 


\title{
Loss of floor plate Netrin-1 impairs midline crossing of corticospinal axons and leads to mirror movements
}

\author{
Oriane Pourchet, ${ }^{1,2}$ Marie-Pierre Morel, ${ }^{2}$ Quentin Welniarz, ${ }^{1}$ Nadège Sarrazin, ${ }^{1}$ Fabio Marti, ${ }^{2}$ Nicolas Heck, ${ }^{2}$ \\ Cécile Galléa, ${ }^{1}$ Mohamed Doulazmi, ${ }^{3}$ Sergi Roig Puiggros, ${ }^{4}$ Juan Antonio Moreno-Bravo, ${ }^{4}$ Marie Vidailhet, ${ }^{1,5}$ \\ Alain Trembleau, ${ }^{2}$ Philippe Faure, ${ }^{2}$ Alain Chédotal, ${ }^{4}$ Emmanuel Roze, ${ }^{1,5,6}$ and Isabelle Dusart $2,6,7, *$ \\ 1Sorbonne Université, CNRS, INSERM, Institut du Cerveau et de la Moelle Épinière (ICM), 75013 Paris, France \\ 2Sorbonne Université, CNRS, INSERM, Institut de Biologie Paris-Seine (IBPS), Neuroscience Paris-Seine (NPS), 75005 Paris, France \\ ${ }^{3}$ Sorbonne Université, CNRS, INSERM, Institut de Biologie Paris-Seine (IBPS), Adaptation Biologique et Vieillissement, 75005 Paris, France \\ ${ }^{4}$ Sorbonne Université, CNRS, INSERM, Institut de la Vision, 75012 Paris, France \\ ${ }^{5}$ Département de Neurologie, Assistance Publique-Hôpitaux de Paris, Hôpital de la Pitié-Salpêtrière, 75013 Paris, France \\ ${ }^{6}$ These authors contributed equally \\ ${ }^{7}$ Lead contact \\ *Correspondence: isabelle.dusart@upmc.fr \\ https://doi.org/10.1016/j.celrep.2020.108654
}

\section{SUMMARY}

In humans, execution of unimanual movements requires lateralized activation of the primary motor cortex, which then transmits the motor command to the contralateral hand through the crossed corticospinal tract (CST). Mutations in NTN1 alter motor control lateralization, leading to congenital mirror movements. To address the role of midline Netrin-1 on CST development and subsequent motor control, we analyze the morphological and functional consequences of floor plate Netrin-1 depletion in conditional knockout mice. We show that depletion of floor plate Netrin-1 in the brainstem critically disrupts CST midline crossing, whereas the other commissural systems are preserved. The only associated defect is an abnormal entry of CST axons within the inferior olive. Alteration of CST midline crossing results in functional ipsilateral projections and is associated with abnormal symmetric movements. Our study reveals the role of Netrin-1 in CST development and describes a mouse model recapitulating the characteristics of human congenital mirror movements.

\section{INTRODUCTION}

Asymmetric voluntary movements, such as opening a bottle or texting a friend, are essential to everyday life. In humans, execution of unimanual movements requires communication between secondary motor areas and primary motor areas, to activate one motor cortex, which then transmits the motor command to the contralateral hand through the crossed corticospinal tract (CST). Congenital mirror movement syndrome (CMM) is a rare neurological disorder characterized by the inability to perform unilateral movements with the hands (Méneret et al., 2015). Patients with CMM experience difficulties in bimanual activities of daily living requiring asymmetric voluntary movements and fine motor coordination. Among the different defects observed in patients with CMM, the most consistent one is the presence of an abnormal corticospinal tract (CST) decussation resulting in corticospinal axons projecting to both sides of the spinal cord (Welniarz et al., 2015). Several mutant mice display abnormal CST decussation (Cohen et al., 1998; Faulkner et al., 2008; Finger et al., 2002; Rünker et al., 2008). However, they do not allow the study of the contribution of abnormal CST decussation to the lateralization of motor control, because of the presence of additional guidance defects in other parts of the central nervous system (CNS). How CST development relates to the lateralization of motor control thus remains unclear.

The NTN1 gene has been associated to CMM (Méneret et al., 2017). It encodes the extracellular protein Netrin-1, which influences the formation and maintenance of multiple tissues (Sun et al., 2011). In the developing nervous system, Netrin-1 acts as a guidance cue required for midline crossing of many commissural axons (Serafini et al., 1996). Mutations in the $\mathrm{Ne}-$ trin-1 receptor genes $D c c$ and Unc5c impair midline crossing of the CST (Finger et al., 2002; Welniarz et al., 2017a), suggesting that Netrin-1 could be required for proper CST decussation. Yet, direct evidence of the contribution of Netrin-1 is still critically lacking because $N t n 1^{K O}$ mice die at birth (Serafini et al., 1996), when corticospinal axons reach the pyramidal decussation (Canty and Murphy, 2008). Shh::cre;Ntn1 $1^{\text {lox/lox }}$ is a viable mouse model, in which Ntn1 depletion is restricted to the floor plate in the regions of the CNS located caudal to the midbrain/hindbrain boundary. Interestingly, midline crossing of spinal cord and hindbrain commissural axons is mostly preserved in this model 
(Dominici et al., 2017; Moreno-Bravo et al., 2019; Varadarajan et al., 2017; Wu et al., 2019). Yet, development of the corticospinal axons, which occurs over a protracted period, has not been investigated in these mice. In the present study, we analyzed the anatomy of the corticospinal tract and the presence of symmetric movements in Shh::cre;Ntn1 $1^{\text {lox/lox }}$ mice to determine the contribution of floor plate Netrin-1 in midline crossing of corticospinal axons and lateralization of motor control.

\section{RESULTS}

Depletion of floor plate-Netrin-1 in the brainstem impairs CST midline crossing at the pyramidal decussation

We first used protein kinase $\mathrm{C}$ gamma $(\mathrm{PKC} \gamma)$ immunochemistry to characterize the anatomy of the CST in adult Shh::cre; $N \operatorname{tn} 1^{\text {lox/lox }}$ mice (Figure 1A). The tract was comparable with control mice (Figure 1A; Figure S1A) down to the medulla level, where corticospinal axons formed two compact ventromedial tracts. In control mice, the CST remained fasciculated until the junction between the brainstem and the spinal cord. There, it turned dorsally and crossed the midline to enter into the dorsal funiculi of the spinal cord, forming the so-called pyramidal decussation. In Shh::cre;Ntn1 $1^{\text {lox/lox }}$ mice, the CST splits into several bundles of axons just before the junction between brainstem and spinal cord. At this level, the CST spread laterally and the pyramidal decussation was thinner than in the control. Accordingly, fewer corticospinal axons were detected in the dorsal funiculi of the spinal cord of Shh::cre;Ntn $1^{\text {lox/lox }}$ mice, and the remaining corticospinal axons were observed in the ventromedial and lateral funiculi of the spinal cord. To assess the laterality of these abnormal corticospinal projections, we injected either tdTomato-expressing adenovirus or biotinylated dextran amine unilaterally in the motor cortex of Shh::cre;Ntn $1^{\text {lox/lox }}$ and control mice. All labeled corticospinal axons reached the contralateral side of spinal cord in control mice. In Shh::cre;Ntn1 $1^{\text {lox/lox }}$ mice, corticospinal axons were detected on both sides of the spinal cord with a variable proportion of axons on each side (Figures 1B and 1C; Video S1; Figure S1B). Floor plate-Netrin-1 is thus required for midline crossing of corticospinal axons at the pyramidal decussation.

To further specify which source of floor plate-Netrin-1 controls CST midline crossing at the pyramidal decussation, we analyzed

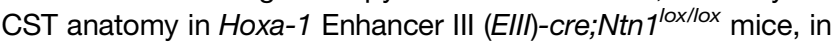
which ablation of floor plate-Ntn1 is restricted to the spinal cord (Figure S2A). Contrary to Shh::cre;Ntn $1^{\text {lox/lox }}$ mice, no alteration of CST trajectory could be detected in these mutants. In particular, all the CST axons crossed the midline at the pyramidal decussation and projected normally into the contralateral spinal cord (Figure S2B). Therefore, CST midline crossing does not rely on the production of floor plate-Netrin-1 by the spinal cord, but rather by the regions located rostral to the pyramidal decussation.

Disruption of the pyramidal decussation in Shh::cre;Ntn $1^{\text {lox/lox }}$ mice is associated with an abnormal position of CST axons within the inferior olive

We previously demonstrated that the Netrin-1 receptor DCC controls CST midline crossing non-cell-autonomously (Welniarz et al., 2017a), arguing against a direct effect of Netrin-1 on CST axons. Depletion of floor plate-Ntn1 rostral to the pyramidal decussation could indirectly disrupt CST midline crossing, by inducing morphological or molecular alterations along the CST trajectory. In Shh::cre; Ntn $1^{\text {lox/lox }}$ mice, the first CST trajectory defects were observed within the caudal medulla. We identified two candidate structures, which depend on Netrin-1 for their development within the caudal medulla and are located on the CST trajectory: the lemniscal decussation (Kubota et al., 2004) and the inferior olive (Bloch-Gallego et al., 1999). The lemniscal decussation, formed by the axons of the dorsal column nuclei (DCN) that project to the contralateral thalamus, could act as a "guiding scaffold" for CST axons (Cohen et al., 1998). To analyze the lemniscal decussation, we performed unilateral injection of a retrograde tracer in the thalamus of Shh::cre;Ntn $1^{\text {lox/lox }}$ and $N \operatorname{tn} 1^{\text {lox } / l o x}$ mice. Similar retrograde labeling was seen in the contralateral DCN of both Shh::cre; Ntn $1^{\text {lox/lox }}$ and Ntn $1^{\text {lox/lox }}$ mice (Figures S3A and S3B), indicating that the lemniscal decussation was preserved in Shh::cre;Ntn $1^{\text {lox/lox }}$ mice.

We then focused on the inferior olive, which surrounds the CST just rostral to the pyramidal decussation. Remarkably, in Shh::cre;Ntn $1^{\text {lox/lox }}$ mutants, the morphology of the inferior olive was altered in its rostral part, with a ventral displacement of the medial subnucleus (Figure 1D). This defect was consistently associated with a mispositioning of CST bundles within the inferior olive. The inferior olive was well formed, and no structural abnormality could be detected before the arrival of CST axons in embryonic day (E) 18 mutants (Video S2). This suggests that the structural alteration of the inferior olive seen in adult Shh::cre;Ntn1 $1^{\text {lox/lox }}$ mice could be the consequence of the abnormal entry of CST axons within the inferior olive.

Abnormalities of descending brain-spinal cord projections are restricted to the CST in Shh::cre;Ntn $1^{\text {lox/lox }}$ mice

Previous characterization of Shh::cre;Ntn1 $1^{\text {lox/lox }}$ mice revealed that guidance of commissural axons of the spinal cord was mostly preserved (Dominici et al., 2017; Moreno-Bravo et al., 2019; Varadarajan et al., 2017; Wu et al., 2019). In addition, we found no alteration of $N$ tn 1 expression in the forebrain, suggesting that the intra-cortical circuitry is preserved in the mutants (Figure S4A). We showed that Ntn1 is expressed at least until post-natal day $(P) 0$ in the floor plate of the brainstem in $N \operatorname{tn} 1^{\text {lox/lox }}$ mice, but not in Shh::cre; Ntn $1^{\text {lox/lox }}$ mice (Figure S4B). We then wondered whether the CST projection defect was accompanied by a disruption of other descending brain-spinal cord projections in Shh::cre;Ntn $1^{\text {lox/lox }}$ mice. To answer this question, we performed unilateral injection of a retrograde tracer in the cervical spinal cord (Figures $2 \mathrm{~A}$ and $2 \mathrm{~B}$ ) and analyzed the laterality of retrograde labeling in several projecting structures, among which were the red nucleus and the pontine and medullary reticular formations, which are known to participate to motor control (Basista and Yoshida, 2020; Lemon, 2008). Although this experiment confirmed the lateralization defect of the CST, we did not detect any alteration in the lateralization of the descending projections from the red nucleus, pontine and medullary reticular formation, parahypothalamic nucleus, paralemniscal nucleus, vestibular nuclei, and Barrington's nucleus (Figure 2; Figure S5). 
A

A

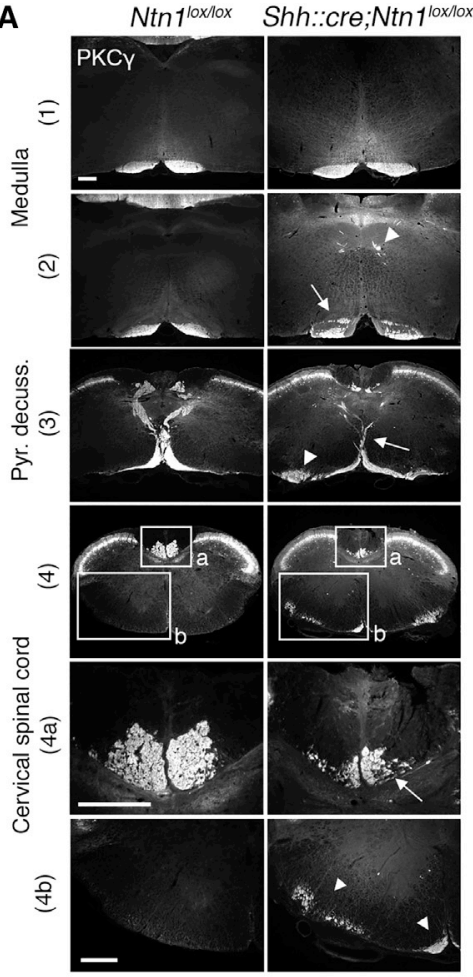

D

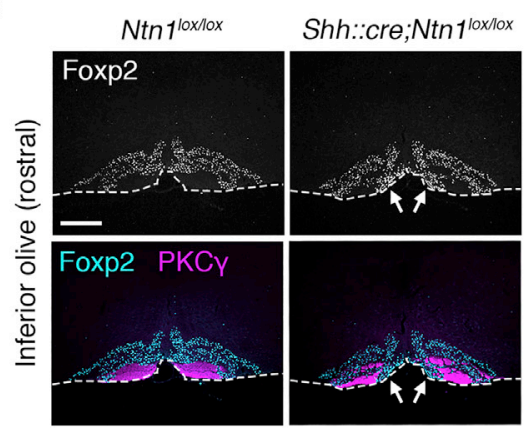

B

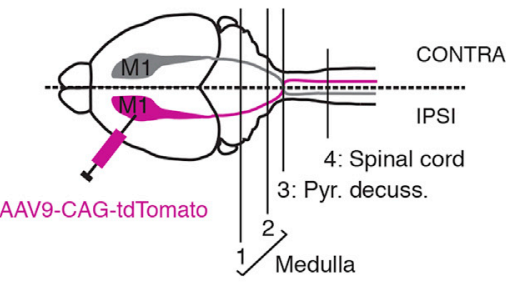

C

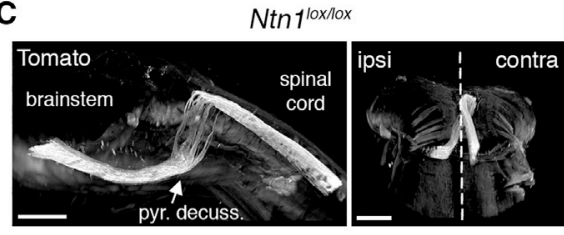

Shh::cre;Ntn1 10x/lox
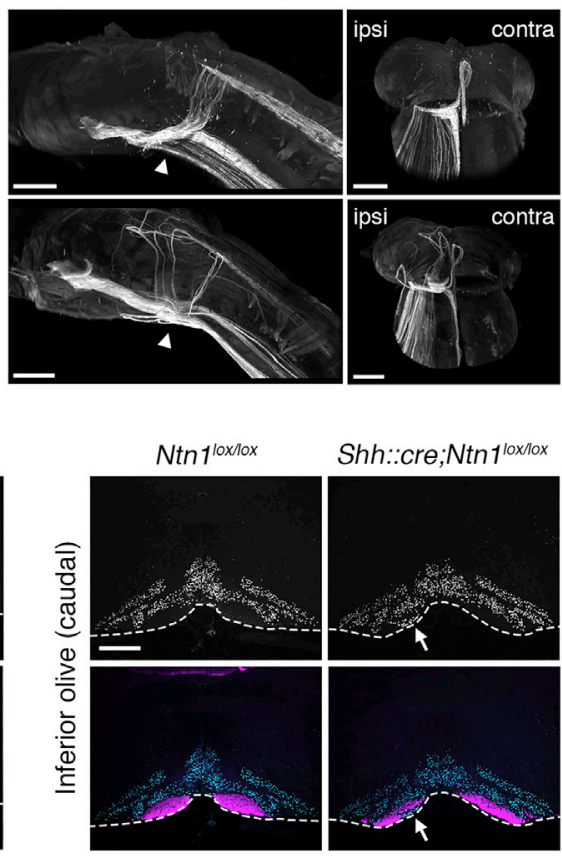

Shh::cre;Ntn1 $10 x / 10 x$

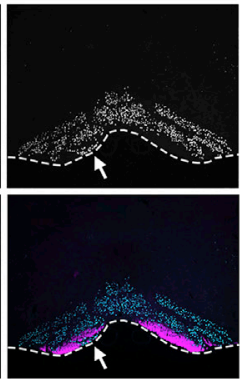

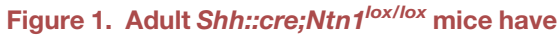
an alteration of CST trajectory at the pyramidal decussation associated to an anatomical defect of the inferior olive (IO)

(A) Coronal sections of adult Ntn1/ox/lox $(n=4)$ and Shh::cre;Ntn $1^{\text {lox/lox }}$ mice $(n=5)$ stained with anti-PKC $\gamma$, a corticospinal tract (CST) marker. (1) Upper and (2) lower medulla, (3) pyramida decussation (pyr. decuss.), and (4) cervical spinal cord. (2) Some CST bundles are separated from the main tract (arrow), and some aberrant dorsal trajectories can be observed (arrowhead); (3) pyramidal decussation is thinner (arrow), and CST spreads laterally (arrowhead); (4) fewer axons are seen in the dorsal funiculi (4a, arrow), and ectopic axons are in ventromedial and lateral funiculi (4b, arrowheads). Scale bars, $250 \mu \mathrm{m}$.

(B) Schematic showing CST tracing strategy and CNS levels for coronal sections shown in (A).

(C) Three-quarter and caudal $3 \mathrm{D}$ views of cleared brainstems of $N$ tn $1^{\text {lox/lox }}$ adult $(n=2)$ and Shh::cre;Ntn1 $1^{\text {lox/lox }}$ mice $(n=3)$ after unilateral tdTomato injection. In Shh::cre;Ntn $1^{\text {lox/lox }}$ mice, many CST axons remain ventral (arrowheads) and do not cross the midline (dotted line). Some axons turn dorsally without crossing the midline (bottom panel). Ipsi and contra are, respectively, ipsilateral and contralateral sides with respect to injection side. Scale bars, $800 \mu \mathrm{m}$.

(D) Coronal sections of 10 of adult $N \operatorname{tn} 1^{\text {lox/lox }}$ $(\mathrm{n}=4)$ and Shh::cre;Ntn1 $1^{\text {lox/lox }}$ mice $(\mathrm{n}=5)$, stained with anti-Foxp2, a marker for 10 neurons. In Shh::cre;Ntn $1^{\text {lox/lox }}$ mice, the medial nucleus of the 10 lies abnormally against the CNS ventral border (dotted line) (arrows); abnormal intermingling of CST bundles and 10 neurons is seen rostrally; and overall $\mathrm{IO}$ anatomy is less altered caudally, but the CST is more flattened and laterally spread compared with control mice. Scale bars, $400 \mu \mathrm{m}$.

Shh::cre;Ntn $1^{\text {lox/lox }}$ mice are therefore an accurate model to analyze the contribution of a CST decussation defect to the lateralization of motor control.

The CST abnormally innervates the ipsilateral spinal cord in Shh:"cre;Ntn $1^{\text {lox/lox }}$ mice

We first characterized the consequences of the CST defect of Shh::cre;Ntn $1^{\text {lox/lox }}$ mice on spinal cord innervation (Figure 3A). In the mouse spinal cord, corticospinal axons leave the white matter to enter the gray matter, mostly at the cervical and lumbar enlargements (Canty and Murphy, 2008). There, they terminate mainly in the dorsal and intermediate horns of the contralateral spinal cord, where they contact interneurons, which eventually transmit the command to forelimb and hindlimb motoneurons (Asante and Martin, 2013; Welniarz et al., 2017b). At both cervical and lumbar enlargements, massive abnormal ipsilateral innervation was found in the gray matter of Shh::cre;Ntn $1^{\text {lox/lox }}$ mice (Fig- ure 3A). To analyze the distribution of corticospinal synapses in the gray matter, we studied the colocalization of VGLUT1 puncta with tomato-positive boutons (Figure $3 \mathrm{~B}$ ). The dorso-ventral distribution of corticospinal synapses was comparable between Shh::cre;Ntn $1^{\text {lox/lox }}$ and control mice, with a higher proportion of synapses detected in the dorsal region compared with the intermediate region. Yet, lateralization of the synapses was altered in Shh::cre;Ntn $1^{\text {lox/lox }}$ mice. In these mutants, synapses were detected on both sides of the gray matter, with a proportion of synapses in the ipsilateral side ranging from $24 \%$ to $70 \%$, whereas they were almost exclusively found in the contralateral gray matter in control mice.

We then sought to determine whether the abnormal ipsilateral CST innervation of Shh::cre;Ntn $1^{\text {lox/lox }}$ mice was functional. We applied unilateral cortical electric stimulations and recorded the evoked electromyographic (EMG) responses in contralateral and ipsilateral gastrocnemii muscles (Figure 3C). In control mice, 
A

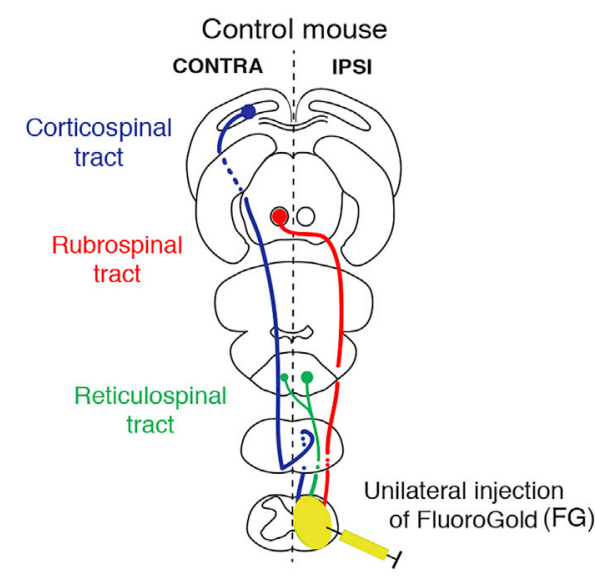

B

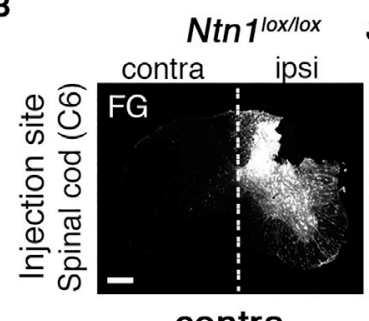

Shh::cre;Ntn $1^{10 x / 10 x}$

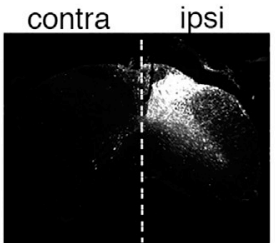

contra

C

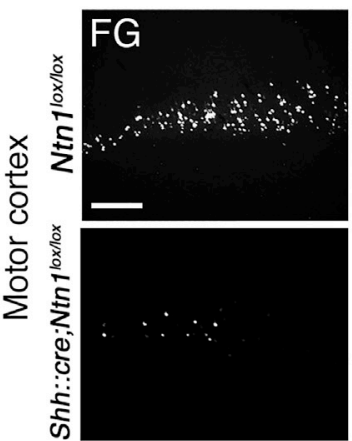

G

Motor cortex

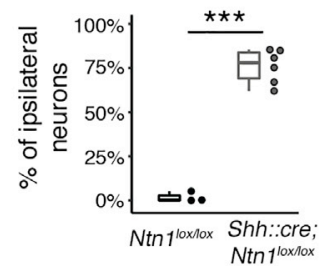

ipsi

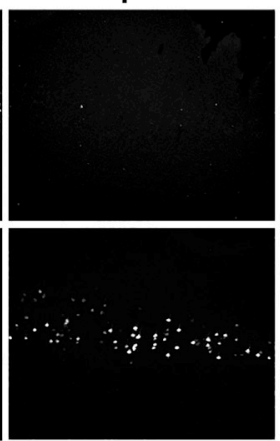

Red nucleus
D

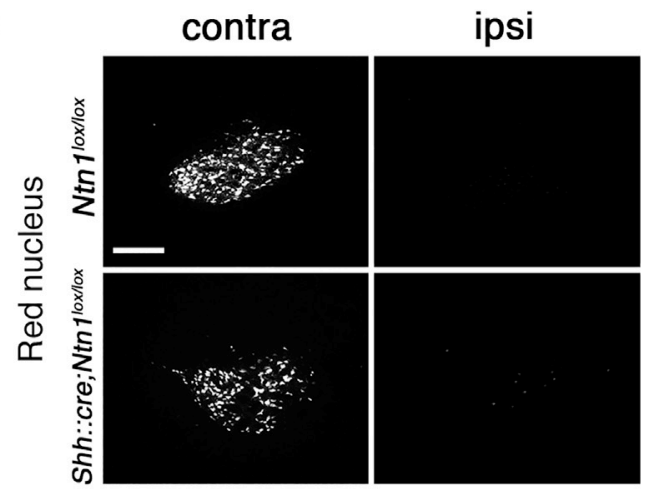

E

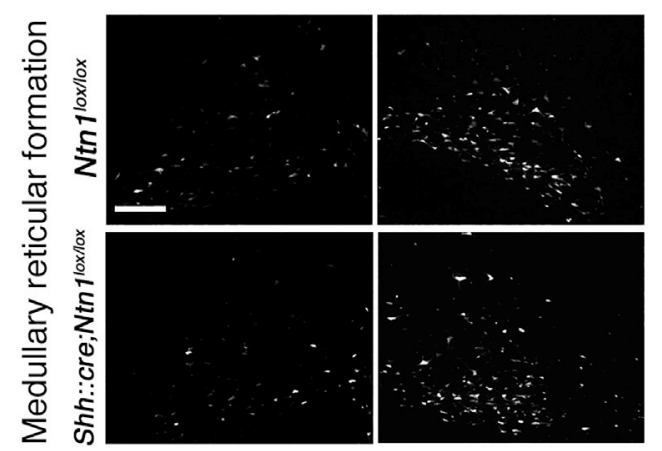

$\mathbf{F}$

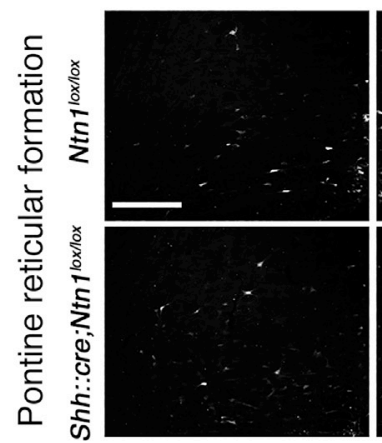

Medullary reticular formation

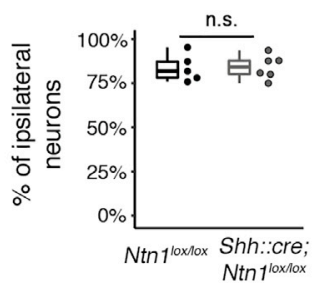

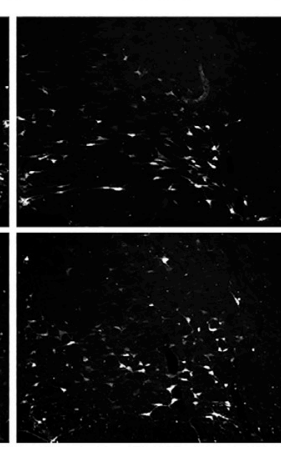

Pontine reticular formation

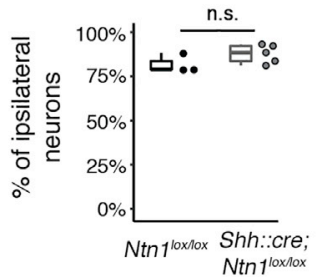

Figure 2. Lateralization of rubrospinal and reticulospinal tracts is preserved in Shh::cre;Ntn $1^{\text {lox/lox }}$ mice

(A) Schematic showing injection site of the retrograde tracer (yellow ellipse) and projection and origin of corticospinal (blue), rubrospinal (red), and reticulospinal tracts (green) in adult control mouse.

(B) Coronal sections after unilateral FluoroGold (FG) injection on the right side of lower cervical spinal cord in Ntn $1^{10 x / l o x}(\mathrm{n}=5)$ and Shh:::cre;Ntn $1^{10 x / l o x}$ mice $(\mathrm{n}=6)$. Scale bar, $250 \mu \mathrm{m}$.

(C-F) Coronal sections of contralateral and ipsilateral motor cortices (C), red nuclei (D), medullary, and pontine reticular formations (E and F) of Ntn $1^{\text {lox/lox }}$ and Shh::Cre;Ntn $1^{\text {lox/lox }}$ mice. Contra and ipsi are, respectively, contralateral and ipsilateral sides with respect to the injection side. Scale bars, $250 \mu \mathrm{m}$.

(G) Proportion of ipsilateral FG-positive neurons in the motor cortex for $n=3 N \operatorname{tn} 1^{10 x / l o x}$ mice (black dots) and $n=6$ Shh::cre;Ntn $1^{10 x / l o x}$ mice (gray dots), ,*** $p<0.001$ (two-sided t test); in the red nucleus and the medullary reticular formation for $n=5 \mathrm{Ntn} 1^{\text {lox/lox }}$ and $n=6$ Shh::cre;Ntn $1^{\text {lox } / \text { lox }}$ mice, $p=0.1173$ (Mann-Whitney) and $\mathrm{p}=0.9148$ (two-sided t test), respectively; and in the pontine reticular formation for $n=3 \mathrm{Ntn} 1^{\text {lox } / \text { lox }}$ and $\mathrm{n}=5$ Shh::cre;Ntn $1^{10 x / / 0 x}$ mice, $p=0.142$ (Mann-Whitney). Data are presented as scatterplot and boxplot, with first and third quartiles, and median. 
A

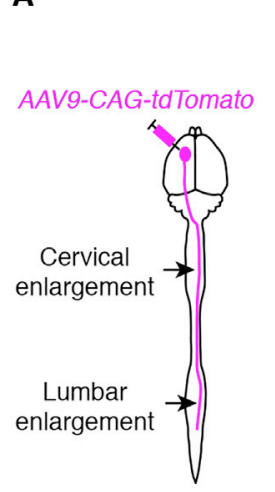

Shh::cre;Ntn $1^{10 \times 10 x}$

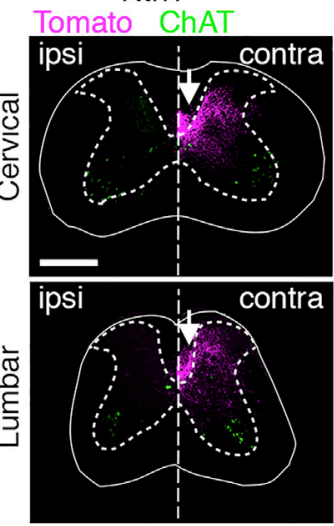

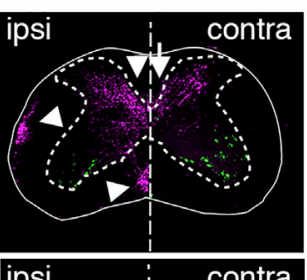

ipsi

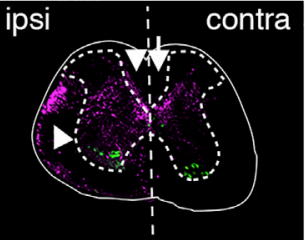

B

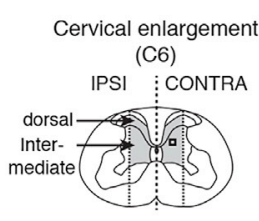

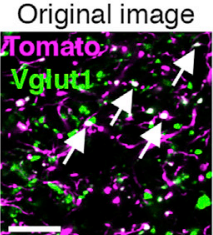

Dorso-ventral distribution of CST synapses

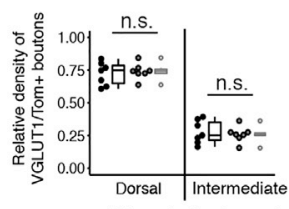

- Ntn1 10x/lox $(\mathrm{n}=7)$
Ipsi- vs. contralateral distribution of CST synapses

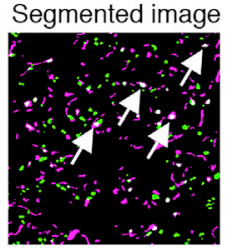

***

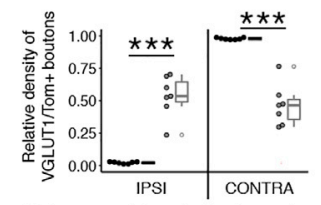

- Shh::cre;Ntn1 10x/ox $(n=7)$

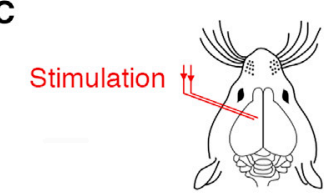

Recording IPSI CONTRA

Shh::cre;Ntn $1^{10 x / 10 x}(\# 3)$

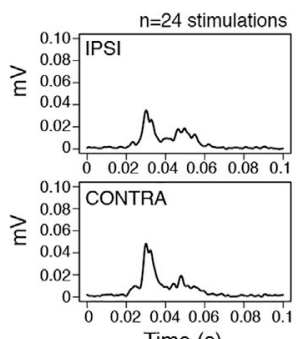

Time (s)

\section{IPSI CONTRA}

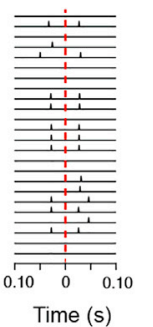

Ntn1 $1^{\text {lox/lox }}(\# 1)$
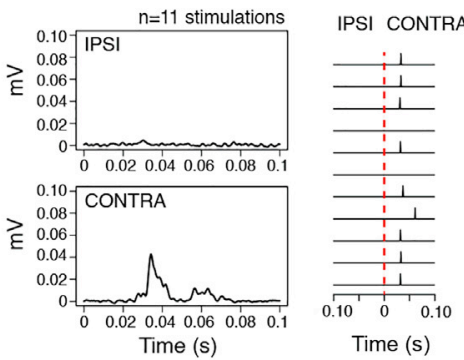

Shh::cre;Ntn $1^{10 x / 10 x}(\# 7)$

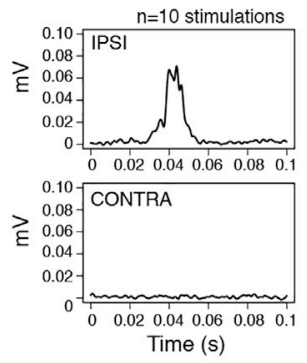

IPSI CONTRA

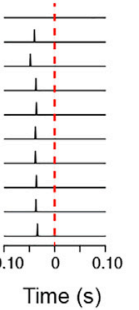

D

Type of EMG response

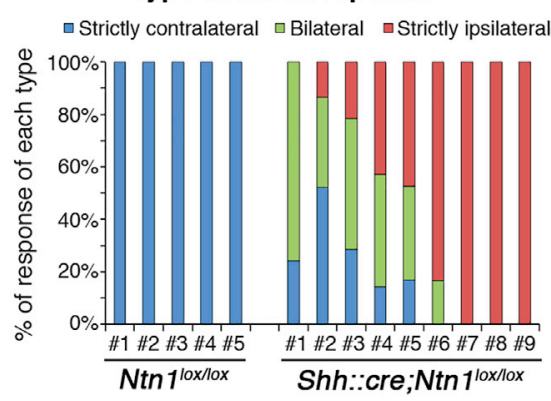

E

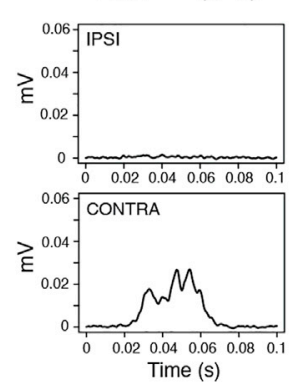

Figure 3. Shh::cre;Ntn1 $1^{\text {lox/lox }}$ mice have abnormal but functional ipsilateral CST projections

(A) Schematic representing unilateral CST labeling and coronal sections of adult Ntn $1^{\text {lox } / l o x}(\mathrm{n}=7)$ and Shh:: cre; Ntn $1^{\text {lox/lox }}$ mice $(\mathrm{n}=7)$ stained with anti-DsRED (revealing Tomato) and anti-ChAT (choline acetyltransferase, motoneuron marker). CST axons are detected in contralateral dorsal funiculus (arrow) in Ntn 1 lox/lox mice, whereas they are mostly seen in ipsilateral ventral and lateral funiculi (arrowheads) in Shh::cre; Ntn $1^{\text {lox/lox }}$ mice and, to a lesser extent, in ipsilateral (arrow) and contralateral (arrowhead) dorsal funiculi. Scale bar, $500 \mu \mathrm{m}$.

(B) Top: schematic of a cervical spinal cord coronal section showing in gray the region of interests (ROIs) where density of CST synapses was analyzed; original and segmented confocal images of a subregion of Shh::cre; Ntn $1^{\text {lox/lox }}$ gray matter; corticospinal synapses (white points, arrows) are identified by the colocalization of anti-DsRED and anti-VGLUT1 (vesicular glutamate transporter 1). Scale bar, $10 \mu \mathrm{m}$. Bottom: relative density of CST synapses in dorsal and intermediate regions, $\mathrm{p}=0.633$ (two-sided t test). Relative density in ipsilateral and contralateral sides, ${ }^{\star \star \star} \mathrm{p}<0.0001$ (two-sided t test). Data are presented as scatterplot and boxplot, with first and third quartiles, and median.

(C) Schematic of electrophysiological procedure. Electric stimulations were delivered in one motor cortex, and evoked EMG were recorded in ipsilateral and contralateral gastrocnemii muscles of adult $N \operatorname{tn} 1^{\text {lox/lox }}(n=5)$ and Shh::cre;Ntn ${ }^{\text {lox/lox }}$ mice $(n=9)$. Examples of average EMG responses from three mice (\#1 Ntn $1^{\text {lox/lox }}$, \#3 and \#7 Shh::cre;Ntn $1^{\text {lox/lox }}$ ) and corresponding raster plots showing different patterns of response.

(D) Unilateral cortical stimulations evoked ipsilateral, bilateral, and/or contralateral EMG responses in Shh::cre;Ntn ${ }^{\text {lox/lox }}$ mice.

(E) Average EMG responses for the five Ntn $1^{\text {lox/lox }}$ and the nine Shh::cre; Ntn $1^{\text {lox/lox }}$ mice. 
cortical stimulation triggered contraction of the contralateral gastrocnemius with corresponding EMG responses (Figures 3C-3E). In Shh::cre;Ntn $1^{\text {lox/lox }}$ mice, similar cortical stimulations elicited either contralateral, bilateral, or ipsilateral EMG responses (Figures 3C-3E). This shows that aberrant ipsilateral corticospinal projections of Shh::cre; Ntn $1^{\text {lox/lox }}$ mice are functional. The ipsilateral-only EMG responses produced by cortical stimulations (Figure 3C, bottom right) further suggest that ipsilateral CST projections are not collateral branches of the contralateral corticospinal neurons but rather independent projections.

\section{Lateralization of voluntary movements is altered in} Shh::Cre;Ntn $1^{\text {lox/lox }}$ mice

We first submitted Shh::cre;Ntn $1^{\text {lox/lox }}$ mice to classic motor tests. Their general motor behavior was mostly undistinguishable from control littermates (Figure 4A), indicating that changes in ratio of contralateral versus ipsilateral corticospinal projections do not significantly influence basic overground locomotion, balance, or motor coordination. We then analyzed the ability of Shh::cre;Ntn1 $1^{\text {lox/lox }}$ mice to perform lateralized coordinated movements for two different types of movements, namely, automatic movements and voluntary movements. Lateralization during automatic movements was investigated with the treadmill locomotion task. In this task, left-right alternation of forelimbs and hindlimbs was preserved in Shh::cre;Ntn1 $1^{\text {lox/lox }}$ mice. The proportion of symmetric movements was very low and similar to control mice (Figure 4B; Video S3). We then used the adaptive locomotion and the exploratory reaching tasks to analyze lateralized motor control during voluntary movements. These two tests have been developed specifically to reveal the presence of abnormal symmetric voluntary movements in mice (Serradj et al., 2014). Interestingly, Shh::cre;Ntn $1^{\text {lox/lox }}$ mice produced a significantly higher proportion of symmetric movements compared with control mice, both in adaptive locomotion and reaching tasks (Figures $4 \mathrm{C}$ and $4 \mathrm{D}$; Video S3). Therefore, lateralized control of voluntary movements is selectively impaired in Shh::cre;Ntn $1^{\text {lox/lox }}$ mice. To definitely exclude any contribution of the spinal circuitry in the production of these abnormal symmetric voluntary movements, we analyzed the behavior of Elllcre; Ntn $1^{\text {lox/lox }}$ mice, in which ablation of floor plate-Ntn1 is restricted to the spinal cord. Contrary to Shh::Cre;Ntn $1^{\text {lox/lox }}$ mice, we found that lateralization of voluntary movements was preserved in these mice (Figure S2C). Overall, these findings reveal that disruption of the pyramidal decussation in Shh::cre; Ntn $1^{\text {lox/lox }}$ mice specifically impairs the production of voluntary asymmetric movements.

\section{DISCUSSION}

Using the viable Shh::cre;Ntn $1^{\text {lox/lox }}$ mouse model, we demonstrated that midline crossing of corticospinal axons is disrupted in the absence of floor plate-Netrin-1. This unveils an unexpected and specific guidance mechanism for corticospinal axons, because floor plate-Netrin-1 was proved to be dispensable or mostly dispensable for midline crossing of hindbrain commissural axons and spinal commissural axons, respectively. Guidance of these ventral commissural axons mainly relies on another source of Netrin-1, produced by the progenitor cells of the ventricular zone (Dominici et al., 2017; Moreno-Bravo et al., 2019; Varadarajan et al., 2017; Wu et al., 2019). This later source of Netrin-1 might also contribute to proper CST decussation, because floor plate-specific depletion of Netrin-1 does not completely abrogate CST midline crossing.

We found that CST midline crossing does not rely on the production of floor plate-Netrin-1 by the spinal cord, but rather by the regions located rostral to the pyramidal decussation. The only associated defect seen in Shh::cre;Ntn $1^{\text {lox/lox }}$ mice is a mispositioning of the CST relative to the inferior olivary nuclei, suggesting that proper inferior olive-CST interaction could play a critical role in CST midline crossing, as proposed before (Rünker et al., 2008). Displacement of CST axons at this level could prevent them from responding correctly to other cues located at the midline. Reduction or absence of pyramidal decussation was also reported in Unc5 $c^{r c m}$ mutants (Finger et al., 2002) and in Dcc ${ }^{\text {Kanga }}$ mice (Finger et al., 2002; Welniarz et al., 2017a) carrying a spontaneous viable mutation in Dcc (Finger et al., 2002). Inter-

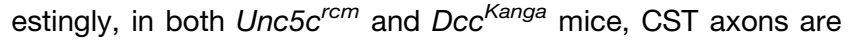
also mispositioned at the level of the inferior olive, suggesting that Dcc, Unc5c, and Netrin-1 could act in a single pathway to indirectly influence CST midline crossing by controlling the inferior olive-CST interaction and/or their relative position. Yet, some phenotypic differences between Dcc or Unc5c mutants and Shh::cre;Ntn $1^{\text {lox/lox }}$ mice should be highlighted. Although the anatomy of inferior olive is altered in Unc5c and Dcc knockout (KO) before the arrival of CST axons (Kim and Ackerman, 2011; Marcos et al., 2009), we could not detect any structural alteration in the inferior olive of E18 Shh::cre;Ntn $1^{\text {lox/lox }}$ mice. Also, intermingling of CST axons and inferior olivary neurons seen in Shh::cre;Ntn $1^{\text {lox/lox }}$ mice has not been reported in Unc5c $c^{r c m}$ or $D c c^{\text {Kanga }}$ mice. These data suggest that depletion of floor plate-Netrin-1 could influence the position of CST axons by preventing their normal segregation from the inferior olive. The mechanism underlying this hypothesis is not understood. At this stage, we cannot exclude the possibility of a direct action of floor plate-Netrin-1 on CST axons through receptors other than DCC or UNC5c. Notably, recent studies (Brignani et al., 2020; Dominici et al., 2017; Moreno-Bravo et al., 2019; Varadarajan et al., 2017) have revealed that the mechanisms by which Netrin-1 influences axon guidance are incredibly more diverse than previously thought.

We found that disrupting the pyramidal decussation does not prevent the further development of misguided corticospinal axons, which follow alternative routes in the spinal cord. These alternate trajectories might correspond to secondary or transitory routes for corticospinal branches during development (Bareyre et al., 2005; Gu et al., 2017). Strikingly, the innervation pattern of the gray matter was relatively well preserved despite the major alteration of CST lateralization and trajectories within the spinal cord. In line with these observations, our electrophysiological recordings further demonstrated that the misguided uncrossed corticospinal projections were functional.

We show that a specific alteration of CST decussation in the mouse is sufficient to recapitulate the CMM phenotype, i.e., abnormal symmetric movements in voluntary tasks, but not in locomotion. The Shh::cre;Ntn1 $1^{\text {lox/lox }}$ mice did not display any "hopping" behavior, i.e., synchronized activity of the 

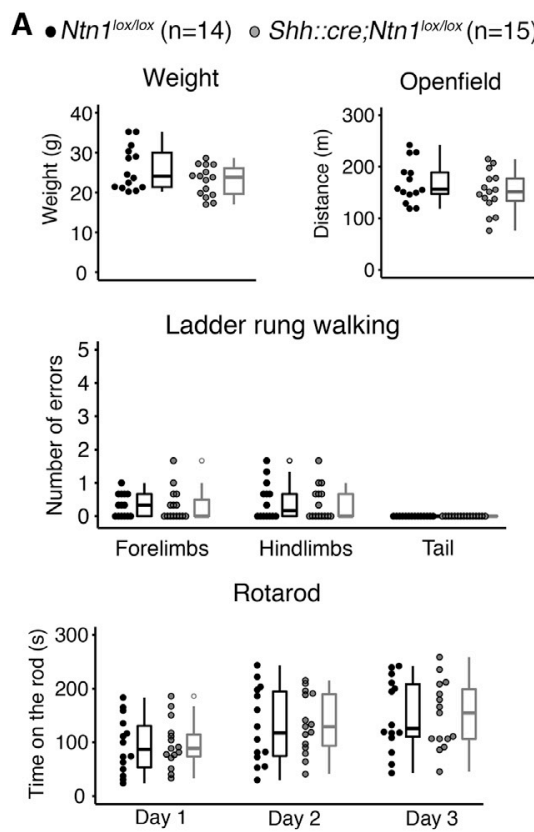

B

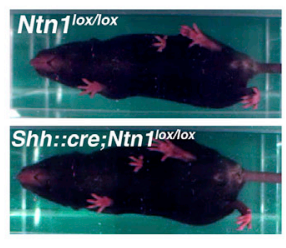

C
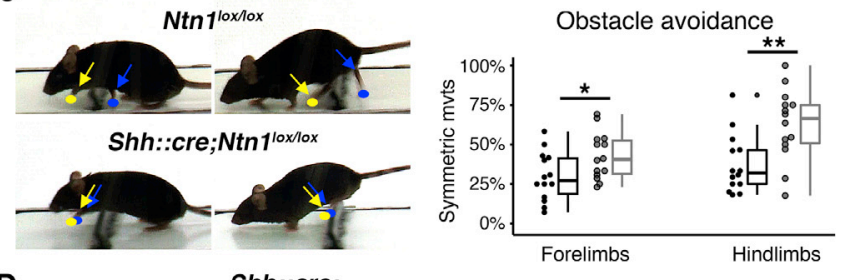

Exploratory reaching

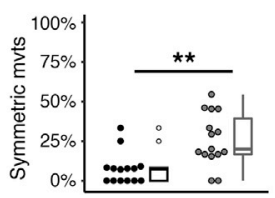

Figure 4. Lateralization of voluntary movements is selectively altered in Shh::cre;Ntn $1^{\text {lox/lox }}$ mice

(A) Ntn1 $1^{\text {lox/lox }}$ (black dots, $\mathrm{n}=14$ ) and Shh::cre;Ntn1 ${ }^{\text {lox/lox }}$ mice (gray dots, $\mathrm{n}=15$ ) have similar weight. $\mathrm{p}=0.084$ (two-sided-t test). General motor behavior of Shh::cre;Ntn $1^{\text {lox/lox }}$ mice is not impaired. They perform as well as their control littermates in open field, on ladder rung task, and on rotarod. $\mathrm{p}_{\mathrm{Openfield}}=0.228$ (two-sided-t test), $\mathrm{p}_{\text {Ladder-Forelimbs }}=0.7151$ (Mann-Whitney), $\mathrm{p}_{\text {Ladder-Hindlimbs }}=0.8471$ (Mann-Whitney), $\mathrm{p}_{\text {Ladder-Tail }}=1$ (Mann-Whitney), $\mathrm{p}_{\text {Rotarod-Day } 1}=0.911$; $\mathrm{p}_{\text {Rotarod-Day2 }}=0.874 ;$ Potarod-Day3 $=0.966$ (two-sided-t test).

(B) Pictures of $N \operatorname{tn} 1^{l o x / l o x}$ and Shh::cre;Ntn $1^{\text {lox/lox }}$ mice performing alternate movements with forelimbs and hindlimbs during treadmill locomotion. Low proportion of symmetric strides in Shh::cre;Ntn1 $1^{\text {lox } / l o x}$ and Ntn $1^{\text {lox/lox }}$ mice, $p_{\text {Forelimbs }}=0.8131$, p Hindlimbs $=0.7151$ (Mann-Whitney).

(C) Pictures of $N \operatorname{tn} 1^{10 x / l o x}$ and Shh::cre;Ntn $1^{\text {lox/lox }}$ mice avoiding the obstacle with, respectively, alternate or synchronous movements of the forelimbs and hindlimbs. Yellow and blue dots/arrows indicate positions of left and right forepaws and hindpaws. Shh::cre;Ntn $1^{\text {lox/lox }}$ mice perform more symmetric movements with forelimbs and hindlimbs during obstacle avoidance task, ${ }^{*} p_{\text {Forelimbs }}=0.03,{ }^{\star *} p_{\text {Hindlimbs }}=0.003$ (two-sided $t$ test).

(D) Pictures of $N t n 1^{l o x / l o x}$ and Shh::cre;Ntn $1^{\text {lox/lox }}$ mice performing, respectively, alternate or synchronous exploratory movements with the forepaws. Shh::cre;Ntn $1^{\text {lox/lox }}$ mice perform more symmetric movements during exploratory reaching task, ${ }^{* *} \mathrm{p}=0.0021$ (Mann-Whitney). Data are presented as scatterplot and boxplot, with first and third quartiles, and median.

homologous limbs during locomotion. The absence of hopping in Shh::cre;Ntn $1^{\text {lox/lox }}$ mice during treadmill locomotion demonstrates that corticospinal projections are not involved in the lateralization of motor control during automatic behaviors, in keeping with previous findings (Serradj et al., 2014). The hopping behavior, reported in $D c c^{\text {Kanga }}$ mice carrying a spontaneous viable mutation in Dcc (Finger et al., 2002), is indeed caused by an impairment of the spinal circuitry (Peng et al., 2018).

In humans, the three main disorders associated with abnormal pyramidal decussation are CMM, X-linked Kallmann syndrome, and Klippel-Feil syndrome (Welniarz et al., 2017b). Mirror movements are the common clinical sign of these syndromes and represent the only clinical manifestation of CMM. The anatomical and functional characterization of the corticospinal projections in our mouse model further indicates that the aberrant CST from one motor cortex projects either to the contralateral or to the ipsilateral side of the spinal cord rather than bilaterally and might not per se be able to transmit the motor command in a strictly symmetric manner. Interestingly, patients with CMM also have an abnormal bilateral pattern of activation in cortical motor areas during unilateral movement execution and preparation (Gallea et al., 2013; Welniarz et al., 2019). We hypothesize that this abnormal activation pattern could reflect a strategy for adapting to aberrant CST projections, eventually resulting in the generation of mirror movements.

In summary, our work reveals a peculiar guidance mechanism for corticospinal axon midline crossing, with a critical dependence on floor plate Netrin-1. Disruption at the pyramidal decussation does not prevent further development of misguided corticospinal axons, which form an abnormal but functional ipsilateral tract. These aberrant corticospinal projections are associated to a selective increase of symmetric movements that can be related to mirror movements described in humans. To date, Shh::cre;Ntn $1^{\text {lox/lox }}$ mice are the only mouse model that recapitulates both the anatomical and behavioral impairments of CMM.

\section{STAR $\star$ METHODS}

Detailed methods are provided in the online version of this paper and include the following:

- KEY RESOURCES TABLE

- RESOURCE AVAILABILITY

O Lead contact 
○ Materials availability

- Data and code availability

- EXPERIMENTAL MODEL AND SUBJECT DETAILS

- METHOD DETAILS

S Surgeries and tracer injections

O Anterograde tracing of the CST with AAV9-CAG-tdTomato

O Anterograde tracing of the CST with BDA

Retrograde tracing of descending tracts with Fluorogold

Retrograde tracing of neurons of the Dorsal Column Nuclei (DCN)

- 2D analysis of brain and spinal cord

O Immunohistochemistry and revelation of BDA

O In situ hybridization (ISH)

- Anatomical data acquisition

○ 3D analysis of the CST

O Tissue preparation

O Whole-Mount Immunostaining and Sample clearing

O $3 \mathrm{D}$ imaging and image processing

O 3D analysis of the inferior olive

- Electrophysiology procedures

O Intracortical stimulation of motor cortex

O Electromyography recordings

$\bigcirc$ Training and behavioral testing

- QUANTIFICATION AND STATISTICAL ANALYSIS

O Corticospinal synapses in the gray matter

○ EMG analysis

O Lateralization of the main motor tracts

O Statistical analysis

\section{SUPPLEMENTAL INFORMATION}

Supplemental Information can be found online at https://doi.org/10.1016/j. celrep.2020.108654.

\section{ACKNOWLEDGMENTS}

This work was funded by grant ANR-18-CE16-0005-02 MOMIC, Fondation Desmarest, and Merz Pharma. We also acknowledge Sarujan Devakumaran (IBPS, France) for his contribution to experiments, France Lam for confocal imaging (IBPS, France), Morgane Belle (Institut de la Vision, France) for lightsheet imaging, Alexis Bemelmans (CEA, France) for producing the AAV9CAG-tdTomato virus, Isabelle Caillé for reviewing the manuscript, and PHENO-ICMice (ICM, France) Core supported by 2 "Investissements d'avenir" (ANR-10- IAIHU-06 and ANR-11-INBS-0011-NeurATRIS), and the "Fondation pour la Recherche Médicale."

\section{AUTHOR CONTRIBUTIONS}

O.P., A.C., E.R., and I.D. designed the study. O.P. and M.-P.M. performed the behavioral analysis. O.P., Q.W., and M.-P.M carried out the 2D anatomical analysis of the CST, and O.P. performed the 3D anatomical analysis. N.H. implemented the segmentation procedure for confocal images. M.-P.M. performed the genotyping. O.P. and F.M. performed the EMG recordings. N.S. carried out the FG injection. S.R.P. and J.A.M.-B. performed the in situ experiments. M.D. carried out the segmentation procedure for retrograde labeling and performed the statistical analyses. O.P., E.R., and I.D. wrote the manuscript. Q.W., F.M., N.H., S.R.P., J.A.M.-B., C.G., M.V., A.T., P.F., and A.C. substantively revised the manuscript.

\section{DECLARATION OF INTERESTS}

The authors declare no competing interests.

Received: April 3, 2020

Revised: October 23, 2020

Accepted: December 22, 2020

Published: January 19, 2021

\section{REFERENCES}

Asante, C.O., and Martin, J.H. (2013). Differential joint-specific corticospinal tract projections within the cervical enlargement. PLoS ONE 8, e74454.

Bareyre, F.M., Kerschensteiner, M., Misgeld, T., and Sanes, J.R. (2005). Transgenic labeling of the corticospinal tract for monitoring axonal responses to spinal cord injury. Nat. Med. 11, 1355-1360.

Basista, M.J., and Yoshida, Y. (2020). Corticospinal Pathways and Interactions Underpinning Dexterous Forelimb Movement of the Rodent. Neuroscience 450, 184-191.

Belle, M., Godefroy, D., Dominici, C., Heitz-Marchaland, C., Zelina, P., Hellal, F., Bradke, F., and Chédotal, A. (2014). A simple method for 3D analysis of immunolabeled axonal tracts in a transparent nervous system. Cell Rep. 9, 11911201.

Bloch-Gallego, E., Ezan, F., Tessier-Lavigne, M., and Sotelo, C. (1999). Floor plate and netrin-1 are involved in the migration and survival of inferior olivary neurons. J. Neurosci. 19, 4407-4420.

Brignani, S., Raj, D.D.A., Schmidt, E.R.E., Düdükcü, Ö., Adolfs, Y., De Ruiter A.A., Rybiczka-Tesulov, M., Verhagen, M.G., van der Meer, C., Broekhoven, M.H., et al. (2020). Remotely produced and axon-derived netrin-1 instructs GABAergic neuron migration and dopaminergic substantia nigra development. Neuron 107, 684-702.e9.

Canty, A.J., and Murphy, M. (2008). Molecular mechanisms of axon guidance in the developing corticospinal tract. Prog. Neurobiol. 85, 214-235.

Cohen, N.R., Taylor, J.S.H., Scott, L.B., Guillery, R.W., Soriano, P., and Furley, A.J.W. (1998). Errors in corticospinal axon guidance in mice lacking the neural cell adhesion molecule L1. Curr. Biol. 8, 26-33.

Dominici, C., Moreno-Bravo, J.A., Puiggros, S.R., Rappeneau, Q., Rama, N. Vieugue, P., Bernet, A., Mehlen, P., and Chédotal, A. (2017). Floor-platederived netrin-1 is dispensable for commissural axon guidance. Nature 545, 350-354.

Faulkner, R.L., Low, L.K., Liu, X.-B., Coble, J., Jones, E.G., and Cheng, H.-J. (2008). Dorsal turning of motor corticospinal axons at the pyramidal decussation requires plexin signaling. Neural Dev. 3, 21.

Finger, J.H., Bronson, R.T., Harris, B., Johnson, K., Przyborski, S.A., and Ackerman, S.L. (2002). The netrin 1 receptors Unc5h3 and Dcc are necessary at multiple choice points for the guidance of corticospinal tract axons. J. Neurosci. 22, 10346-10356.

Gallea, C., Popa, T., Hubsch, C., Valabregue, R., Brochard, V., Kundu, P., Schmitt, B., Bardinet, E., Bertasi, E., Flamand-Roze, C., et al. (2013). RAD51 deficiency disrupts the corticospinal lateralization of motor control. Brain 136, 3333-3346.

Gilles, J.-F., Dos Santos, M., Boudier, T., Bolte, S., and Heck, N. (2017). DiAna, an ImageJ tool for object-based 3D co-localization and distance analysis. Methods 115, 55-64.

Gu, Z., Kalambogias, J., Yoshioka, S., Han, W., Li, Z., Kawasawa, Y.I., Pochareddy, S., Li, Z., Liu, F., Xu, X., et al. (2017). Control of species-dependent cortico-motoneuronal connections underlying manual dexterity. Science 357, 400-404.

Gul-Mohammed, J., Arganda-Carreras, I., Andrey, P., Galy, V., and Boudier, T. (2014). A generic classification-based method for segmentation of nuclei in 3D images of early embryos. BMC Bioinformatics 15, 9.

Harfe, B.D., Scherz, P.J., Nissim, S., Tian, H., McMahon, A.P., and Tabin, C.J. (2004). Evidence for an expansion-based temporal Shh gradient in specifying vertebrate digit identities. Cell 118, 517-528. 
Kim, D., and Ackerman, S.L. (2011). The UNC5C netrin receptor regulates dorsal guidance of mouse hindbrain axons. J. Neurosci. 31, 2167-2179.

Kubota, C., Nagano, T., Baba, H., and Sato, M. (2004). Netrin-1 is crucial for the establishment of the dorsal column-medial lemniscal system. J. Neurochem. 89, 1547-1554.

Lemon, R.N. (2008). Descending pathways in motor control. Annu. Rev. Neurosci. 31, 195-218.

Li, X., and Lufkin, T. (2000). Cre recombinase expression in the floorplate, notochord and gut epithelium in transgenic embryos driven by the Hoxa-1 enhancer III. Genesis 26, 121-122.

Marcos, S., Backer, S., Causeret, F., Tessier-Lavigne, M., and Bloch-Gallego, E. (2009). Differential roles of Netrin-1 and its receptor DCC in inferior olivary neuron migration. Mol. Cell. Neurosci. 41, 429-439.

Méneret, A., Welniarz, Q., Trouillard, O., and Roze, E. (2015). Congenital mirror movements: from piano player to opera singer. Neurology 84, 860.

Méneret, A., Franz, E.A., Trouillard, O., Oliver, T.C., Zagar, Y., Robertson, S.P., Welniarz, Q., Gardner, R.J.M., Gallea, C., Srour, M., et al. (2017). Mutations in the netrin-1 gene cause congenital mirror movements. J. Clin. Invest. 127, 3923-3936.

Moreno-Bravo, J.A., Roig Puiggros, S., Mehlen, P., and Chédotal, A. (2019). Synergistic Activity of Floor-Plate- and Ventricular-Zone-Derived Netrin-1 in Spinal Cord Commissural Axon Guidance. Neuron 101, 625-634.e3.

Peng, J., Ferent, J., Li, Q., Liu, M., Da Silva, R.V., Zeilhofer, H.U., Kania, A., Zhang, Y., and Charron, F. (2018). Loss of Dcc in the spinal cord is sufficient to cause a deficit in lateralized motor control and the switch to a hopping gait. Dev. Dyn. 247, 620-629.

Renier, N., Adams, E.L., Kirst, C., Wu, Z., Azevedo, R., Kohl, J., Autry, A.E., Kadiri, L., Umadevi Venkataraju, K., Zhou, Y., et al. (2016). Mapping of Brain Activity by Automated Volume Analysis of Immediate Early Genes. Cell 165, 1789-1802.

Rünker, A.E., Little, G.E., Suto, F., Fujisawa, H., and Mitchell, K.J. (2008). Semaphorin-6A controls guidance of corticospinal tract axons at multiple choice points. Neural Dev. 3, 34.
Serafini, T., Colamarino, S.A., Leonardo, E.D., Wang, H., Beddington, R., Skarnes, W.C., and Tessier-Lavigne, M. (1996). Netrin-1 is required for commissural axon guidance in the developing vertebrate nervous system. Cell 87, 1001-1014.

Serradj, N., Paixão, S., Sobocki, T., Feinberg, M., Klein, R., Kullander, K., and Martin, J.H. (2014). EphA4-mediated ipsilateral corticospinal tract misprojections are necessary for bilateral voluntary movements but not bilateral stereotypic locomotion. J. Neurosci. 34, 5211-5221.

Starkey, M.L., Barritt, A.W., Yip, P.K., Davies, M., Hamers, F.P.T., McMahon, S.B., and Bradbury, E.J. (2005). Assessing behavioural function following a pyramidotomy lesion of the corticospinal tract in adult mice. Exp. Neurol. 195, 524-539.

Sun, K.L.W., Correia, J.P., and Kennedy, T.E. (2011). Netrins: versatile extracellular cues with diverse functions. Development 138, 2153-2169.

Varadarajan, S.G., Kong, J.H., Phan, K.D., Kao, T.-J., Panaitof, S.C., Cardin, J., Eltzschig, H., Kania, A., Novitch, B.G., and Butler, S.J. (2017). Netrin1 Produced by Neural Progenitors, Not Floor Plate Cells, Is Required for Axon Guidance in the Spinal Cord. Neuron 94, 790-799.e3.

Welniarz, Q., Dusart, I., Gallea, C., and Roze, E. (2015). One hand clapping: lateralization of motor control. Front. Neuroanat. 9, 75

Welniarz, Q., Morel, M.-P., Pourchet, O., Gallea, C., Lamy, J.-C., Cincotta, M., Doulazmi, M., Belle, M., Méneret, A., Trouillard, O., et al. (2017a). Non cellautonomous role of DCC in the guidance of the corticospinal tract at the midline. Sci. Rep. 7, 410

Welniarz, Q., Dusart, I., and Roze, E. (2017b). The corticospinal tract: Evolution, development, and human disorders. Dev. Neurobiol. 77, 810-829.

Welniarz, Q., Gallea, C., Lamy, J.-C., Méneret, A., Popa, T., Valabregue, R., Béranger, B., Brochard, V., Flamand-Roze, C., Trouillard, O., et al. (2019). The supplementary motor area modulates interhemispheric interactions during movement preparation. Hum. Brain Mapp. 40, 2125-2142.

Wu, Z., Makihara, S., Yam, P.T., Teo, S., Renier, N., Balekoglu, N., MorenoBravo, J.A., Olsen, O., Chédotal, A., Charron, F., and Tessier-Lavigne, M. (2019). Long-Range Guidance of Spinal Commissural Axons by Netrin1 and Sonic Hedgehog from Midline Floor Plate Cells. Neuron 101, 635-647.e4. 


\section{STAR $\star M E T H O D S$}

\section{KEY RESOURCES TABLE}

\begin{tabular}{|c|c|c|}
\hline REAGENT or RESOURCE & SOURCE & IDENTIFIER \\
\hline \multicolumn{3}{|l|}{ Antibodies } \\
\hline rabbit anti-PKC $\gamma$ & Santa Cruz & Cat\# sc-211, RRID:AB_632234 \\
\hline guinea-pig anti-VGLUT1 & Millipore & Cat\# AB5905, RRID:AB_2301751 \\
\hline goat anti-ChAT & Millipore & Cat\# AB144P, RRID:AB_2079751 \\
\hline rabbit anti-DsRED & Living Colors & Cat\# 632496, RRID:AB_10013483 \\
\hline goat anti-FOXP2 & Abcam & Abcam Cat\# ab1307, RRID:AB_1268914 \\
\hline \multicolumn{3}{|l|}{ Bacterial and virus strains } \\
\hline AAV9-CAG-tdTomato & MIRCen & $\mathrm{N} / \mathrm{A}$ \\
\hline \multicolumn{3}{|l|}{ Experimental models: organisms/strains } \\
\hline Mouse: Ntn1 flox (conditional knockout) & Dominici et al., 2017 & N/A \\
\hline Mouse: B6.Cg-Shhtm1(EGFP/cre)Cjt/J & Jackson Laboratories & $\begin{array}{l}\text { Cat\# JAX:005622; RRID: } \\
\text { IMSR_JAX:005622 }\end{array}$ \\
\hline $\begin{array}{l}\text { Mouse: B6.Cg-Gt(ROSA)26Sortm9(CAG- } \\
\text { tdTomato)Hze/J }\end{array}$ & Jackson Laboratories & $\begin{array}{l}\text { Cat\# JAX:007909; RRID: } \\
\text { IMSR_JAX:007909 }\end{array}$ \\
\hline Mouse: Tg(Hoxa1-cre)1Tlu ; (EllI::cre) & (Li and Lufkin, 2000) & MGI Cat\# 5000124, RRID:MGI:5000124 \\
\hline \multicolumn{3}{|l|}{ Oligonucleotides } \\
\hline $\begin{array}{l}\text { In situ probe for Ntn1 exon3: Forward 5- } \\
\text { ATGATGCGCGCTGTGTGG-3 }\end{array}$ & Dominici et al., 2017 & $\mathrm{~N} / \mathrm{A}$ \\
\hline $\begin{array}{l}\text { In situ probe for Ntn1 exon3: Reverse 5- } \\
\text { AGCTCCGAGTCGTCTTCG-3 }\end{array}$ & Dominici et al., 2017 & $\mathrm{~N} / \mathrm{A}$ \\
\hline \multicolumn{3}{|l|}{ Software and algorithms } \\
\hline Adobe Photoshop CS6/CC & Adobe & RRID:SCR_014199 \\
\hline Adobe Illustrator CS5/CC & Adobe & RRID:SCR_010279 \\
\hline Inspector Pro & LaVision BioTec & $\mathrm{N} / \mathrm{A}$ \\
\hline Imaris $x 64$ v8 & Oxford Instruments & $\begin{array}{l}\text { RRID: SCR_007370; } \\
\text { https://imaris.oxinst.com/ }\end{array}$ \\
\hline \multirow[t]{2}{*}{ Leica LAS X software } & Leica Microsystems & RRID:SCR_013673 \\
\hline & $\mathrm{NIH}$ & $\begin{array}{l}\text { RRID:SCR_003070 https://imagej.nih.gov/ } \\
\text { ij/download.html }\end{array}$ \\
\hline IMovie & Apple & $\begin{array}{l}\text { https://support.apple.com/downloads/ } \\
\text { imovie }\end{array}$ \\
\hline Spike2 & CED & RRID:SCR_000903 \\
\hline
\end{tabular}

\section{RESOURCE AVAILABILITY}

Lead contact

Further information and requests for resources and reagents should be directed to and will be fulfilled by the Lead Contact, Isabelle Dusart (isabelle.dusart@upmc.fr).

Materials availability

This study did not generate new unique reagents.

Data and code availability

The data that supports the findings of this study are available from the lead author upon reasonable request. 


\section{EXPERIMENTAL MODEL AND SUBJECT DETAILS}

The following mouse strains were used: Shh::cre (Jackson laboratory), Ntn1 ${ }^{\text {lox }}$ (given by P. Melhen, Lyon) and Ai9 RosatdTomato (Rosa ${ }^{\text {Tom }}$; Jackson lab). Shh::cre and Ntn1 $1^{\text {lox }}$ were previously described in (Harfe et al., 2004) and (Dominici et al., 2017) respectively. They were maintained on a C57BL/6J background and were genotyped by PCR as described previously. Adult (2-4 months) and embryonic (E14 and E18 stages) mice of either sex were used. All animal procedures were approved by the Regional Animal Experimentation Ethics Committee C2EA-05 Charles Darwin and the French Ministère de l'éducation nationale de l'enseignement supérieur et de la recherche (projects $\left.\mathrm{N}^{\circ} 01558.03,2018042815492966\right)$. We strictly performed these approved procedures.

\section{METHOD DETAILS}

Surgeries and tracer injections

Buprenorphine (Buprecare) was injected subcutaneously $30 \mathrm{~min}$ before the surgery at $0.1 \mathrm{mg} / \mathrm{kg}$. During surgeries and injections, mice were anesthetized with isoflurane and body temperature was maintained at $37^{\circ} \mathrm{C}$ by a heating pad.

Anterograde tracing of the CST with AAV9-CAG-tdTomato 2-month old adult mice (7 Ntn1 $1^{\text {lox/lox }}$ and 7 Shh::cre; Ntn $1^{\text {lox/lox }}$ mice) were placed in a stereotaxic frame (Kopf Instrument) and lidocaïne (Xylovet) was injected subcutaneously at $3 \mathrm{mg} / \mathrm{kg} 5 \mathrm{~min}$ before the surgery. AAV9-CAG-tdTomato (MIRCen) was diluted in saline to a final titer of $1.7 .10^{13} \mathrm{GC} / \mathrm{mL}$. Four injections of $0.5 \mu \mathrm{L}$ of this AAV solution were administered at $1.6 \mathrm{~nL} / \mathrm{s}$ in the left motor cortex using the following coordinates: $0.75 \mathrm{~mm}$ rostral to Bregma, 1 and $2 \mathrm{~mm}$ lateral, at a depth of $1 \mathrm{~mm}$ for the 2 first injections and $0.25 \mathrm{~mm}$ caudal to Bregma, 1 and $2 \mathrm{~mm}$ lateral, at a depth of $1 \mathrm{~mm}$ for the 2 last injections. At each injection point, the needle was left in place for 2 min before and $4 \mathrm{~min}$ after the injection to avoid leakage. After surgery, the wound was cleansed and the skin sutured. Analysis was carried out 3 weeks after injection.

\section{Anterograde tracing of the CST with BDA}

Unilateral injections of biotinylated dextran amine (BDA, MW 10 000, SIGMA) were performed in the left motor cortex of 2-month old

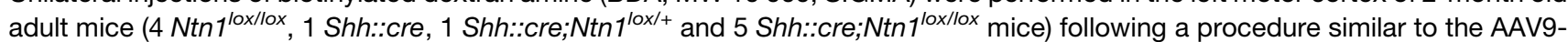
CAG-tdTomato injection procedure. BDA was diluted in saline to a final concentration of $10 \%$. Six injections of $0.2 \mu \mathrm{L}$ were administered at $1.6 \mathrm{~nL} / \mathrm{s}$ in the left motor cortex using the following coordinates: $1 \mathrm{~mm}$ rostral to Bregma, 1 and $2 \mathrm{~mm}$ lateral, at a depth of $1 \mathrm{~mm}$ for the first couple of injections, $0.25 \mathrm{~mm}$ caudal to Bregma, 1 and $2 \mathrm{~mm}$ lateral, at a depth of $1 \mathrm{~mm}$ for the $2 \mathrm{~s} \mathrm{couple} \mathrm{of} \mathrm{injections}$ and $1 \mathrm{~mm}$ caudal to Bregma, 1 and $2 \mathrm{~mm}$ lateral, at a depth of $1 \mathrm{~mm}$ for the last couple of injections. At each injection point, the needle was left in place for 3 min before and after the injection to avoid leakage. After surgery, the wound was cleansed and the skin sutured. Analysis was carried out 2 weeks after injection.

\section{Retrograde tracing of descending tracts with Fluorogold}

Retrograde tracing was performed unilaterally on 2-month-old adult mice. $13 \mathrm{Ntn} 1^{\text {lox/lox }}$ and 18 Shh::cre;Ntn $1^{\text {lox } / l o x}$ mice were injected but only $5 \mathrm{Ntn} 1^{\text {lox/lox }}$ and $6 \mathrm{Shh}: \mathrm{:cre;} \mathrm{Ntn} 1^{\mathrm{lox} / \mathrm{lox}}$ mice were retained for the analysis after verification of absence of leakage of the tracer across the midline, see the QUANTIFICATION section). The lower cervical spinal cord was exposed and $0.4-0.6 \mu \mathrm{L}$ of a $4 \%$ Fluorogold (Fluorochrome) solution in $0.9 \%$ saline was injected at $2 \mathrm{~nL} / \mathrm{s}$ on the right side of C6-C7. After the injection, the needle was kept in place for an additional $3 \mathrm{~min}$ to avoid leakage of tracer. The wound was closed by suturing the paraspinal muscles and skin. Carprofène (rimadyl) was injected subcutaneously at $5 \mathrm{mg} / \mathrm{kg}$ on the wound and Buprenorphine (Buprecare, $1 \mathrm{mg} / \mathrm{kg}$ per os) was added to the drinking water. Analysis was carried out 2 weeks after injection.

\section{Retrograde tracing of neurons of the Dorsal Column Nuclei (DCN)}

2-month-old adult mice ( $3 \mathrm{Ntn} 1^{\text {lox/lox }}$ and $3 \mathrm{Shh}:: \mathrm{cre}$;Ntn $1^{\text {lox/lox }}$ mice) were placed in a stereotaxic frame (Kopf Instrument) and lidocaïne (Xylovet) was injected subcutaneously at $3 \mathrm{mg} / \mathrm{kg} 5 \mathrm{~min}$ before the surgery. A $4 \%$ Fluorogold (Fluorochrome) solution in $0.9 \%$ saline was injected at $1.6 \mathrm{~nL} / \mathrm{s}$ unilaterally in the left thalamus of the mice, using the following coordinates: $2 \mathrm{~mm}$ rostral to Bregma, $1.8 \mathrm{~mm}$ lateral, at a depth of $3.5 \mathrm{~mm}$ for the first injection, and $1.7 \mathrm{~mm}$ rostral to Bregma, $1.8 \mathrm{~mm}$ lateral, at a depth of $3.6 \mathrm{~mm}$ for the second injection. At each injection point, the needle was left in place for $4 \mathrm{~min}$ after the injection to avoid leakage. After surgery, the wound was cleansed and the skin sutured. Analysis was carried out 3 weeks after injection.

In all cases, mice were killed by an intraperitoneal injection of Euthasol (150mg/kg) followed by perfusion with $4 \%$ paraformaldehyde in $0.12 \mathrm{M}$ phosphate buffer, pH 7.4 (PFA).

2D analysis of brain and spinal cord

After perfusion, brains and spinal cords were collected and post-fixed in the same fixative for $4 \mathrm{~h}$ at $4^{\circ} \mathrm{C}$. Samples were cryoprotected in a solution of $20 \%$ sucrose in $0.12 \mathrm{M}$ phosphate buffer $(\mathrm{pH} 7.4)$. Brains were frozen in isopentane at $-35^{\circ} \mathrm{C}$, and stored at $-80^{\circ} \mathrm{C}$ 
until processing. Spinal cords were embedded in Tissue-Teck OCT (VWR, Fontenay sous bois, France), frozen in isopentane at $-30^{\circ} \mathrm{C}$ and stored at $-20^{\circ} \mathrm{C}$ until processing. Samples were cut at $30 \mu \mathrm{m}$ in coronal plane with a cryostat (Leica Microsystems) and serially mounted on slides.

Immunohistochemistry and revelation of BDA

Sections were washed in PBS and blocked for $1 \mathrm{~h}$ with a PBSGT solution (1X PBS, $0.2 \%$ gelatin, $0.25 \%$ Triton X-100) containing $0.1 \mathrm{M}$ lysine (Merck). Sections were then incubated overnight at room temperature in the PBSGT solution with the following primary antibody: rabbit anti-PKC $\gamma$ (1/100, Santa Cruz, sc-211), goat anti-FOXP2 (1/500, Abcam ab1307), guinea-pig anti-VGLUT1 (1/ 3000, Millipore, AB5905), goat anti-ChAT (1/300, Millipore, AB144P), rabbit anti-DsRED (1/500, Living Colors, 632496), followed by $2 \mathrm{~h}$ incubation in species-specific secondary antibody directly conjugated to fluorophores (Cy3 or Cy5 from Jackson ImmunoResearch or Alexa Fluor 488 from Invitrogen). Sections were mounted in Mowiol (Calbiochem, La Jolla, CA).

BDA labeling was revealed by streptavidin conjugated to the Cy5 fluorophore (1/400, Invitrogen) that was added to the primary antibody solution.

\section{In situ hybridization (ISH)}

Riboprobe synthesis

cDNAs encoding mouse Ntn1 exon 3 were used. The in vitro transcription was carried out by using the Promega kit (Promega, Charbonnières, France) and probes were labeled with digoxigenin-11-d-UTP (Roche Diagnostics, Indianapolis, IN).

Tissue preparation

E14 embryos (3 Ntn $1^{\text {lox/lox }}$ and 3 Shh::cre;Ntn $1^{\text {lox/lox }}$ ) and E18/P0 mice (2Ntn $1^{\text {lox/lox }}$ and 3 Shh::cre; Ntn $1^{\text {lox/lox }}$ ) were fixed by immersion in $4 \%$ PFA over night at $4^{\circ} \mathrm{C}$. Samples were cryoprotected in a solution of $20 \%$ sucrose in $0.12 \mathrm{M}$ phosphate buffer (pH7.4), frozen in isopentane at $-35^{\circ} \mathrm{C}$ and then cut in coronal plane at $20 \mu \mathrm{m}$ with a cryostat (Leica).

In situ hybridization protocol

Brain sections were postfixed for $10 \mathrm{~min}$ in $4 \%$ PFA, washed in PBS, treated with proteinase $\mathrm{K}$ (20 $\mu \mathrm{g} / \mathrm{ml}$; Invitrogen) for 2 min, postfixed for $5 \mathrm{~min}$ in 4\% PFA, washed in PBS, acetylated, washed in PBS 1\% Triton X-100. Slides were incubated 2 hours at room temperature with hybridization buffer ( $50 \%$ formamide, 5x SSC, 5x Denhardt's, $250 \mu \mathrm{g} / \mathrm{ml}$ yeast tRNA, and $500 \mu \mathrm{g} / \mathrm{ml} \mathrm{herring} \mathrm{sperm} \mathrm{DNA,}$ $\mathrm{pH}$ 7.4). Then, tissue sections were hybridized overnight at $72^{\circ} \mathrm{C}$ with riboprobes (1/200). After hybridization, sections were rinsed for 2 hours in $0.2 x \mathrm{SSC}$ at $72^{\circ} \mathrm{C}$, and blocked in $0.1 \mathrm{M}$ Tris, $\mathrm{pH} 7.5,0.15 \mathrm{M} \mathrm{NaCl}(\mathrm{B} 1)$ containing $10 \%$ normal goat serum (NGS) for 1 hour at room temperature. After blocking, slides were incubated overnight at room temperature with anti-DIG antibody conjugated with the alkaline phosphatase (1/5,000, Roche Diagnostics) in B1 containing 1\% NGS. After washing in B1 buffer, the alkaline phosphatase activity was detected by using nitroblue tetrazolium chloride $(337.5 \mu \mathrm{g} / \mathrm{ml})$ and 5-bromo-4-chloro-3-indolyl phosphate $(175 \mu \mathrm{g} /$ $\mathrm{ml}$ ) (Roche Diagnostics). Sections were mounted in Mowiol.

\section{Anatomical data acquisition}

Images of PKC $\gamma$ staining, BDA CST tracing, virus-labeled corticospinal innervation of cervical and lumbar spinal cord and retrograde tracing were acquired on Leica DMR microscope, under identical conditions of magnification, illumination and exposure. Gray level images were captured using MetaView software (Universal Imaging Corporation, Ropper Scientific, France). In situ hybridization slides were scanned with a Nanozoomer (Hamamatsu). Brightness and contrast were adjusted using Adobe Photoshop.

For corticospinal synapses in the gray matter, a Leica SP5 confocal microscope equipped with a 63x objective (oil immersion, 1.4 Numerical Aperture) was used to acquire image stacks with pixel size of $160 \mathrm{~nm}$ and z-step of $300 \mathrm{~nm}$. Image stacks of VGLUT1 were denoised with median filter.

3D analysis of the CST

$2 \mathrm{Ntn} 1^{\text {lox/lox }}$ and 3 Shh::cre;Ntn $1^{\text {lox/lox }}$ mice were injected unilaterally with AAV9-CAG-tdTomato virus in the motor cortex (cf. Anterograde tracing of the CST).

\section{Tissue preparation}

After perfusion, brains and spinal cords were collected and post-fixed in the same fixative overnight at $4^{\circ} \mathrm{C}$. Samples were pretreated with methanol before immunostaining. Samples were dehydrated with 50\% (1h30), 80\% (1h30) methanol/PBS and 100\% methanol for $2 \times 1 \mathrm{~h} 30$. Samples were chilled at $4^{\circ} \mathrm{C}$ and bleached overnight in $6 \% \mathrm{H}_{2} \mathrm{O}_{2}$ in methanol at $4{ }^{\circ} \mathrm{C}$. Samples were rinced in methanol, and rehydrated with 100\% (2x1h30), 80\% (1h30), 50\% (1h30) methanol/PBS and PBS 1X (1h30).

Whole-Mount Immunostaining and Sample clearing

Samples were first incubated at room temperature on a rotating shaker in a solution (PBSGT) of PBS $1 \mathrm{X}$ containing $0.2 \%$ gelatin and 0.5\% Triton X-100 (Sigma-Aldrich) for 3 days. Samples were next transferred to PBSGT containing 0.1\% saponin and anti-DsRED (1/ 500 , Living Colors, 632496) and placed at $37^{\circ} \mathrm{C}$ with rotation for 10 days. This was followed by six washes of $1 \mathrm{~h}$ in PBSGT at room temperature. Next, samples were incubated in PBSGT containing $0.1 \%$ saponin and a donkey anti-rabbit conjugated to the Cy3 fluorophore (1/200, Jackson Immuno Research) for 2 days at $37^{\circ} \mathrm{C}$ with rotation. After six washes of $1 \mathrm{~h}$ in PBSGT at room temperature, 
samples were cleared using a methanol clearing protocol, adapted from iDISCO+ protocol (Renier et al., 2016) found at https:// transparent-human-embryo.com.

\section{D imaging and image processing}

3D imaging was performed with an ultramicroscope using Inspector Pro software (LaVision BioTec). 3D volume and movies were generated using Imaris software. Crystals that might form from secondary antibody precipitation were eliminated using the surface tool by creating a mask around each volume.

\section{D analysis of the inferior olive}

\section{Tissue preparation}

$3 \mathrm{Ntn} 1^{\text {lox/lox }}$ and 4 Shh::cre;Ntn $1^{\text {lox/lox }}$ embryos were collected at E18 and fixed by intra-cardiac perfusion with $4 \%$ paraformaldehyde in $0.12 \mathrm{M}$ phosphate buffer, $\mathrm{pH} 7.4$ (PFA). After perfusion, brains were collected and post-fixed in the same fixative overnight at $4^{\circ} \mathrm{C}$. Whole-Mount Immunostaining and Sample clearing

Samples were first incubated at room temperature on a rotating shaker in a solution (PBSGT) of PBS $1 \mathrm{X}$ containing $0.2 \%$ gelatin and 0.5\% Triton X-100 (Sigma-Aldrich) for 3 days. Samples were next transferred to PBSGT containing $0.1 \%$ saponin and anti-Foxp2 (1/ 500 , abcam, ab1307) and placed at $37^{\circ} \mathrm{C}$ with rotation for 12 days. This was followed by six washes of $1 \mathrm{~h}$ in PBSGT at room temperature. Next, samples were incubated in PBSGT containing $0.1 \%$ saponin and a donkey anti-goat conjugated to the Cy3 fluorophore (1/600, Jackson Immuno Research) for 1 day at $37^{\circ} \mathrm{C}$ with rotation. After six washes of $1 \mathrm{~h}$ in PBSGT at room temperature, samples were cleared using the 3DISCO protocol(Belle et al., 2014) found at https://transparent-human-embryo.com.

3D imaging and morphological analysis of the inferior olive

3D imaging was performed with an ultramicroscope using Inspector Pro software (LaVision BioTec). 3D volumes were analyzed using Imaris software. Superimposition of 3D volumes of Foxp2-labeled inferior olive of Ntn $1^{\text {lox/lox }}$ and Shh::Cre; Ntn $1^{\text {lox/lox }}$ mice allowed to compare the morphology of this structure between the 2 genotypes. Virtual sectioning of the inferior olives was performed using the oblique slicer tool to further compare the position of the different inferior olive subnuclei between Ntn $1^{\text {lox/lox }}$ and Shh::cre; Ntn $1^{\text {lox } / l o x}$ mice. Movies were generated using Imaris software.

\section{Electrophysiology procedures}

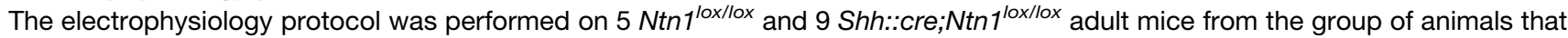
underwent the behavioral tests.

\section{Intracortical stimulation of motor cortex}

Anesthesia was induced with intraperitoneal injection of chloral hydrate $(400 \mathrm{mg} / \mathrm{kg})$ to render the animal unresponsive to paw pinch. Animals were then placed in a stereotaxic frame. Body temperature was maintained at $37^{\circ} \mathrm{C}$ by a heating pad. A craniotomy was made over the hindlimb area of $\mathrm{M} 1$.

We used home-made bipolar tungsten electrodes $(250 \mu \mathrm{m}$ apart, impedance $=6.5 \mathrm{~K} \Omega)$. Electrode penetration was made perpendicular to the pial surface at $1 \mathrm{~mm}$ depth. The stimulation was applied in the hindlimb motor area (between 1 to $2.0 \mathrm{~mm}$ lateral to bregma, between 0,5 to 1.5 caudal to bregma).

10 to 20 stimulations $(40 \mathrm{~ms}$ duration train of $0.6 \mathrm{~ms}$ monophasic pulses at $350 \mathrm{~Hz}$ ) were delivered every $10 \mathrm{~s}$ by a constant current stimulator (Digitimer, Ltd). For a given site, we started at low current and increased the amplitude until the lowest current that consistently produced a motor effect (in $>50 \%$ of trials). A maximal current of $25 \mathrm{~mA}$ was used; if no response was evoked at this intensity, the site was considered nonresponsive and the electrode was moved to another site (within the hindlimb motor area of the same hemisphere). The same procedure was then performed on the motor cortex of the opposite hemisphere.

\section{Electromyography recordings}

We recorded electromyographic (EMG) responses from the gastrocnemii muscles bilaterally evoked by the stimulation of one motor cortex. 2 homemade silver recording electrodes were inserted $5 \mathrm{~mm}$ apart in left and right gastrocnemii muscles. The proper placement of the electrodes was controled by noting increased EMG activity upon passive plantar flexion. The EMG recordings were made with a differential $\mathrm{AC}$ amplifier and then digitized at $12.5 \mathrm{kHz}$ and analyzed with Spike2 program (CED). Raw EMG was smoothed and rectified after recording with Spike 2.

\section{Training and behavioral testing}

The first behavioral study (described in Figure 4) was conducted on 15 Shh::cre;Ntn ${ }^{\text {lox/lox }}$ and 14 Ntn $1^{\text {lox/lox }}$ control mice aged between 8 and 12 weeks; a second behavioral study (mentionned in Figure S2C) was conducted as a control experiment suggested by the reviewers, on 12 Elll::cre; Ntn $1^{\text {lox/lox }}$ and $13 \mathrm{Ntn} 1^{\text {lox/lox }}$ control mice aged between 8 and 12 weeks; This second behavioral study comprised only the partial SHIRPA protocol, the openfield, the treadmill and the exploratory reaching experiment. For both studies, male and female mice were used. We verified that the repartition of male and female did not differ between groups $\left(\right.$ Chi2, $\mathrm{p}_{\mathrm{group} 1}=$ $\left.0.893 ; p_{\text {group } 2}=0.561\right)$. All the behavioral tests were performed blindly to the genotype. For the first three days, the mice were habituated to being handled by the experimenters in order to limit stress. Mice were then tested with a partial SHIRPA protocol (grasping, 
clasping and auditory tests were performed, and whisker state was evaluated) in order to rule out major neurological abnormalities. Open field

The open field test was used to evaluate spontaneous activity and locomotion: mice were placed in the center of a $0.25-\mathrm{m}^{2}$ arena and allowed to explore freely for 5 minutes. During this time, they were tracked and recorded with a camera fixed above the arena, and the total walking distance was calculated with Topscan software.

Ladder

The ladder test apparatus (Locotronic) consists of a $124 \mathrm{~cm} \times 8 \mathrm{~cm}$ corridor with a floor composed of 78 bars each $1 \mathrm{~cm}$ apart. The mice were made to cross the corridor and the number of slips of the forelimbs, hindlimbs and tail was automatically detected by 158 infrared captors placed on the corridor walls (sampling frequency $1000 \mathrm{~Hz}$ ). The test was repeated three times for each mouse and the sum of errors throughout the three trials was calculated. This test evaluates the precision and coordination of limb positioning. Treadmill

Mice were placed on a transparent treadmill $(14 \mathrm{~cm} \times 6 \mathrm{~cm})$ moving at $12 \mathrm{~cm} / \mathrm{s}$. After a short training session, the mice had to run for ten seconds, during which period the positioning of their paws was recorded by a camera fixed under the apparatus. The proportion of symmetric and asymmetric strides was calculated after excluding frames in which the mouse was not running.

Rotarod

The accelerating Rotarod (BIOSEB) consists of a horizontal rod $3 \mathrm{~cm}$ in diameter, turning on its longitudinal axis. The training phase consisted of walking on the rod at a rotational speed varying from 4 to $40 \mathrm{rpm}$ for one minute. The mice were then subjected to four trials in which the speed of rotation increased gradually from $4 \mathrm{rpm}$ to $40 \mathrm{rpm}$ over $5 \mathrm{~min}$. Time spent on the rod was recorded and averaged for the 4 trials. The test was repeated three days in a row with the same procedure, except that the training session was performed only on the first day.

Reaching exploratory behavior

When placed in a new environment, as a glass cylinder, mice engage in "reaching" exploratory behavior, in which they contact walls with their forepaws (Serradj et al., 2014; Starkey et al., 2005). This contact can be made with the two paws simultaneously (symmetric movement) or independently (asymmetric). Ten reaching movements were recorded with a video camera and then examined frameby-frame to calculate the number of asymmetric and symmetric movements.

Obstacle avoidance test

This test allows to evaluate adaptative locomotion(Serradj et al., 2014; Starkey et al., 2005). It consists in placing the mouse on an obstructed treadmill, on which 2 obstacles were mounted one small (5mm height) and one large (10mm). The treadmill was moving at $10 \mathrm{~cm} / \mathrm{s}$ for 2 minutes (acclimatization phase) and $15 \mathrm{~cm} / \mathrm{s}$ for the 2 following minutes. The mice were accustomed to the task for two days and were recorded with a video camera on the third day. The number of alternate steps (asymmetric movements) and hops (symmetric movements) over the obstacles was calculated for both the forelimbs and the hindlimbs during the $15 \mathrm{~cm} / \mathrm{s}$ session. If the mouse was pausing before avoiding the obstacle, the movement was not considered in the analysis.

\section{QUANTIFICATION AND STATISTICAL ANALYSIS}

$p$ values and samples sizes can be found in the figure legends.

\section{Corticospinal synapses in the gray matter}

Distribution analysis of corticospinal synapses in the gray matter were carried out from confocal images of spinal cord sections of 7 Ntn $1^{\text {lox/lox }}$ and 7 Shh::cre;Ntn $1^{\text {lox/lox }}$ mice injected unilaterally with AAV9-CAG-tdTomato virus in the motor cortex.

At cervical and lumbar enlargement, the majority of corticospinal terminations were detected in the medial half of the laminae III-V (defined as the "dorsal" region) and the medial half of the laminae V-VII (defined as the "intermediate" region) in both Ntn 1 lox/lox and Shh::cre;Ntn $1^{\text {lox/lox }}$ mice. For each region of interest (ROI), three image stacks of 80 microns width and 8 microns depth were acquired on the ipsilateral and contralateral sides of the gray matter.

Segmentation was performed in three-dimensions (3D) by iterative thresholding and MESR algorithm(Gilles et al., 2017; Gul-Mohammed et al., 2014). User-defined constraints (i.e., minimum intensity threshold, minimum and maximum volumes) were included in the procedure. The segmentation was automated with macros calling functions from the ImageJ plugin 3DImageSuite. Colocalization was detected in 3D by 3DImageSuite ImageJ plugin as overlap between segmented objects from the two channels.

For each section, we calculated the density of colocalization per ROI as the average of colocalization densities of the 3 sampling regions from this $\mathrm{ROI}$. The densities of colocalization per $\mathrm{ROI}$ of the two consecutive sections were then averaged. The relative distribution of colocalization among the $4 \mathrm{ROIs}$ (ispilateral dorsal, ipsilateral intermediate, contralateral dorsal, contralateral intermediate) was obtained by dividing the colocalization density of each ROI by the sum of the densities of the 4 ROls. This allowed us to compare the relative distribution of the corticospinal synapses (VGLUT1/Tomato colocalization) among the 4 ROIs between animals independently from tracing differences.

EMG analysis

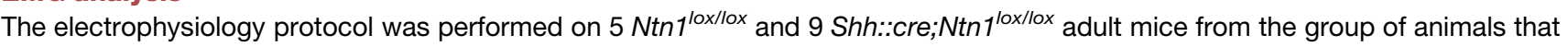
underwent the behavioral tests. Data are presented as mean of EMG obtained from 10 to 20 stimulations of one or the two motor 
cortices (7 out of 14 mices). Proportion of each type of responses ("strictly" contralateral, "strictly" ispilateral and bilateral) to stimulation are calculated on effective motor contraction only.

\section{Lateralization of the main motor tracts}

We first verified that the retrograde tracer FluoroGold (FG) was correctly injected on the right side of the cervical enlargement (C6) and

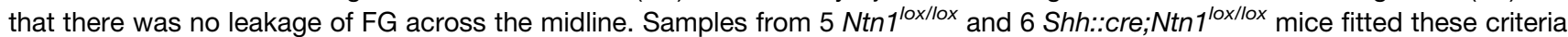
(35\% of the injected mice) and were included in the subsequent analysis. The structures of interest, i.e., motor cortex, red nucleus, medullary reticular formation, pontine reticular formation, parahypothalamic nucleus, paralemniscal nucleus, vestibular nuclei, Barrington's nucleus, were captured on 2 to 5 consecutive sections (depending on the structure) with a Leica DMR microscope, under identical conditions of magnification, illumination and exposure. FG labeled neurons were segmented with ImageJ, using a selective threshold. After thresholding, we applied two algorithms of mathematical morphology: SKIZ (Skeleton by Influence Zones) and Watershed. At this step, animals for which fewer than 90 FG-labeled neurons could be segmented for one structure of interest were excluded from the analysis of this particular structure. For the other cases, the number of segmented neurons on each side (ipsilateral or contralateral to the injection site) of each structure was reported and the ratio of ipsilateral segmented neurons over the total number of segmented neurons was calculated for each structure.

\section{Statistical analysis}

Data were analyzed with SPSS statistical software version 24.0 (Chicago, Illinois, USA). Normality in the variable distributions was assessed by the Shapiro-Wilk test. Furthermore, the Levene's test was performed to probe homogeneity of variances across groups. Variables that failed the Shapiro-Wilk or the Levene's test were analyzed with nonparametric statistics using the one-way KruskalWallis analysis of variance on ranks followed by Nemenyi test post hoc and Mann-Whitney rank sum tests for pairwise multiple comparisons. Correlations were estimated with the Spearman method. Variables that passed the normality test were analyzed with ANOVA followed by the Bonferroni post hoc test for multiple comparisons, or with Student's t test when comparing two groups. Paired data were analyzed by repeated-measures ANOVA with two factors, followed by the Bonferroni post hoc test for multiple comparisons. Correlations were estimated with the Pearson method. Categorical variables were compared using Pearson's $\chi^{2}$ test or Fisher's exact test. 
Cell Reports, Volume 34

\section{Supplemental Information}

\section{Loss of floor plate Netrin-1 impairs \\ midline crossing of corticospinal axons}

\section{and leads to mirror movements}

Oriane Pourchet, Marie-Pierre Morel, Quentin Welniarz, Nadège Sarrazin, Fabio Marti, Nicolas Heck, Cécile Galléa, Mohamed Doulazmi, Sergi Roig Puiggros, Juan Antonio Moreno-Bravo, Marie Vidailhet, Alain Trembleau, Philippe Faure, Alain Chédotal, Emmanuel Roze, and Isabelle Dusart 

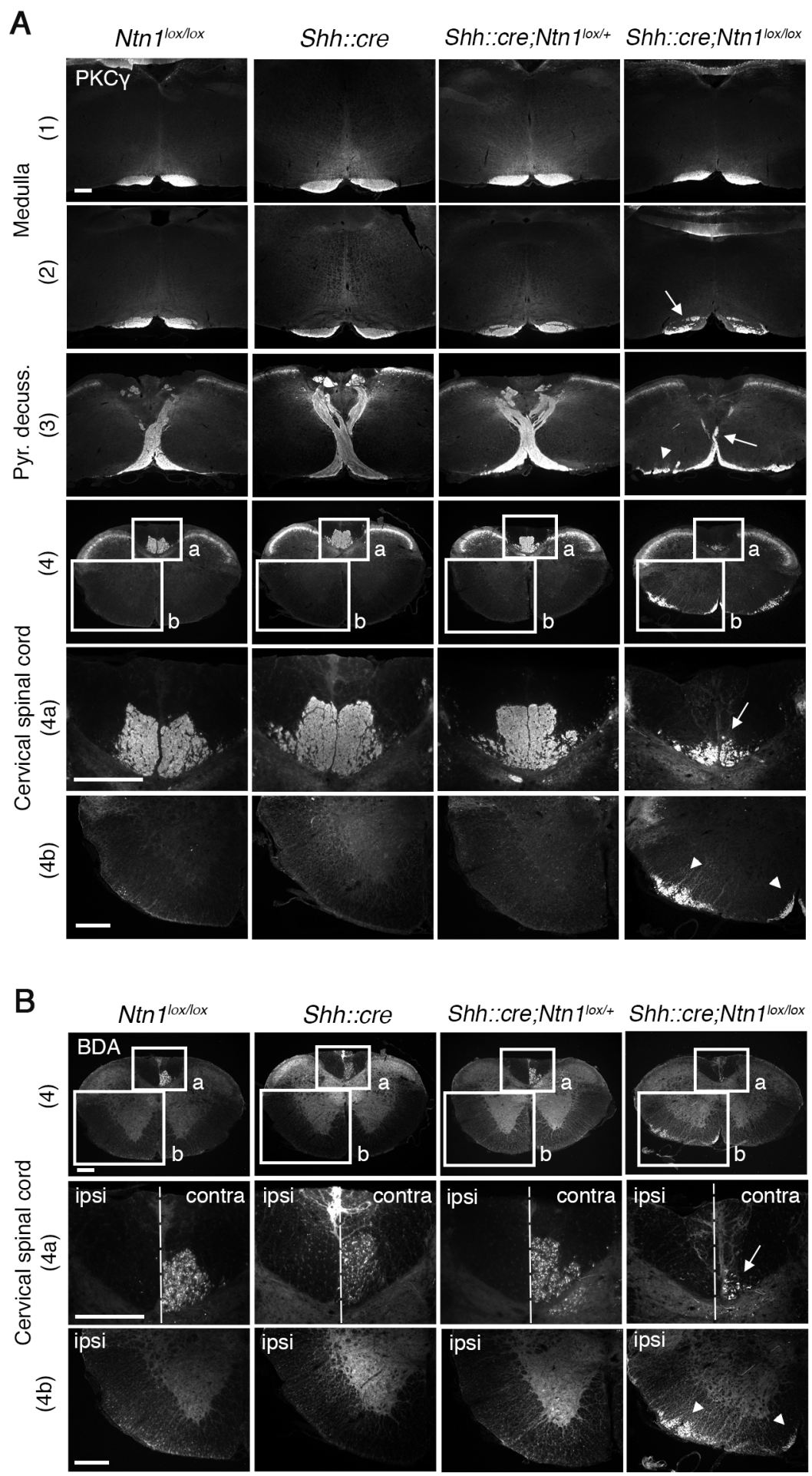
Figure S1. Corticospinal tract guidance is disrupted at the pyramidal decussation in Shh::cre; Ntn1 ${ }^{l o x / l o x}$ mice. Related to Figure 1

(A) Coronal sections of adult $N \operatorname{Nin} 1^{\text {loxllox }}(\mathrm{n}=4)$, Shh::cre $(\mathrm{n}=1), \operatorname{Shh}:: \operatorname{cre} ; \operatorname{Ntn} 1^{\operatorname{lox} /+}(\mathrm{n}=1)$ and Shh::cre;Ntn1 ${ }^{\text {lox/lox }}$ mice $(\mathrm{n}=5)$ stained with anti-PKC $\gamma$, a marker of the CST, at different levels: (1) upper and (2) lower medulla, (3) pyramidal decussation (pyr. decuss.), and (4) cervical spinal cord. The CST is similar in all genetic background in (1). In (2), several CST axon bundles are separated from the main tract (arrow) in Shh::cre;Ntnl ${ }^{\text {loxllox }}$ (arrow). This

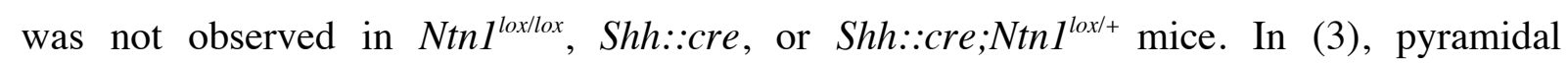
decussation of Shh::cre;Ntn1 $1^{\text {lox/lox }}$ is thinner (arrow) compared to Ntn $1^{\text {lox/lox }}$, Shh::cre, or Shh::cre;Ntn1 ${ }^{l o x /+}$ mice and the CST spreads laterally (arrowhead). In (4), less axons are detected in the dorsal funiculi of Shh::cre; NtnI $I^{\text {loxlox }}$ (4a, arrow, dotted line is the midline) and some axons are seen in ectopic positions in the ventromedial and lateral funiculi (4b, arrowheads). (B) Coronal sections of the cervical spinal cord presented in (A) with revelation of biotinylated dextran amine (BDA), after unilateral injection in the left motor cortex. Fewer corticospinal axons are detected in the contralateral dorsal funiculus in Shh::cre;Ntn1 $1^{\text {lox/lox }}$ mice (4a, arrow) compared to $N \operatorname{tn} 1^{l o x / l o x}$, Shh::cre, or Shh::cre;Ntnl ${ }^{l o x /+}$ mice. In these mice, some ectopic CST axons are detected in the ipsilateral ventromedial and lateral funiculi (4b, arrowheads). Ipsi and contra are respectively ipsilateral and contralateral sides with respect to the injection side. Scale bars, $250 \mu \mathrm{m}$. 
A

High Ntn1 expression

$\square$ Low Ntn1 expression

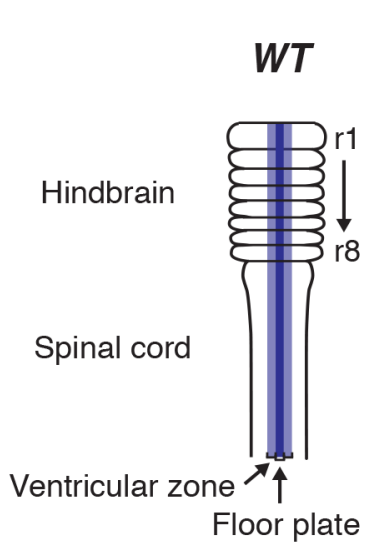

C

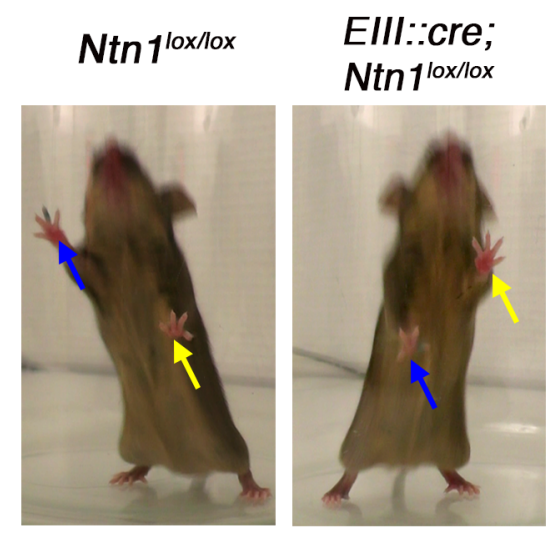

B

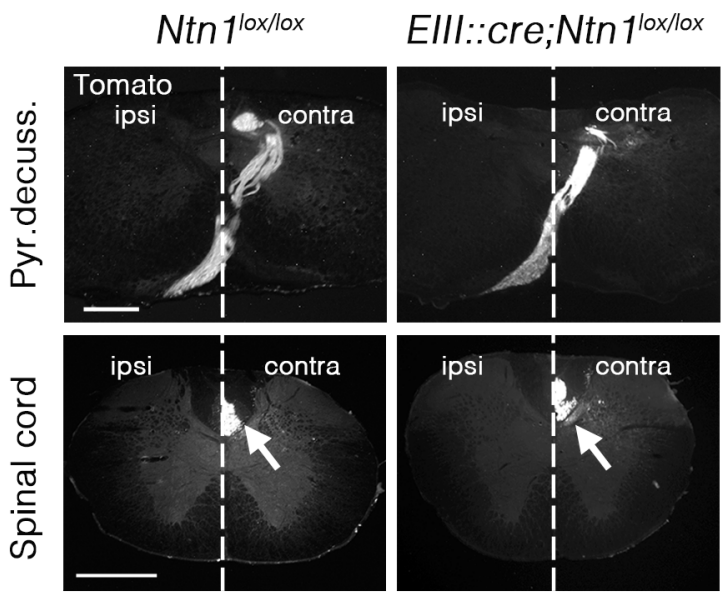

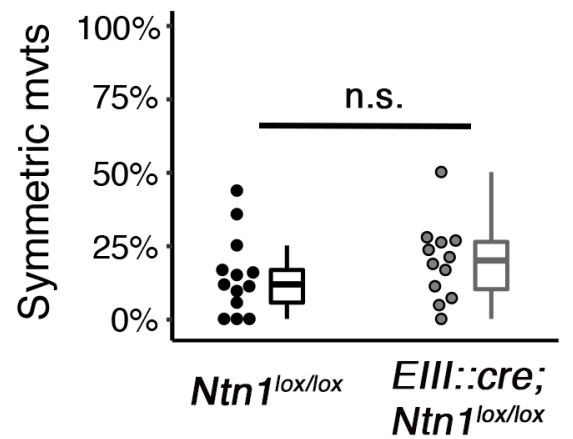


Figure S2. Spinal cord-specific depletion of FP-Ntn1 does not impair CST midline crossing at the pyramidal decussation nor lateralization of voluntary motor control. Related to Figures 1 and 4

(A) Schematic showing Ntn1 expression (in purple) in the neural tube of WT mice (left) and after conditional ablation in Shh::cre;Ntn1 ${ }^{\text {lox/lox }}$ (middle) and EIII::cre;Ntnl ${ }^{\text {lox/lox }}$ (right) mice. r, rhombomere. (B) Coronal sections of adult $N \operatorname{tn} 1^{\text {lox/lox }}(\mathrm{n}=3)$ and EIII::cre; $\operatorname{Ntn} 1^{\text {lox/lox }}(\mathrm{n}=2)$ mice at the level of the pyramidal decussation (top) and spinal cord (bottom) after unilateral injection of a tdTomato-expressing adenovirus in the left motor cortex. At the pyramidal decussation, all the CST axons cross the midline (dotted line) in both $N \operatorname{tn} 1^{\text {lox/lox }}$ and EIII::cre;Ntn $1^{\text {loxlox }}$ mice. In the spinal cord, CST axons are detected in the contralateral dorsal funiculus (white arrow). Pyr. decuss., pyramidal decussation; ipsi, contra are respectively ipsilateral and contralateral sides with respect to the injection side; dotted line is the midline. Scale bars, $500 \mu \mathrm{m}$. (C) Left: Pictures of a Ntn $1^{\text {lox/lox }}$ mouse and a EIII::cre;Ntn $1^{\text {lox/lox }}$ mouse performing alternate exploratory movements with the forepaws. Yellow and blue arrows indicate the positions of the left and right forepaws respectively. Right: The proportion of symmetric movements during exploratory reaching is comparable between EIII::cre;Ntn1 $1^{\text {lox/lox }}$ $(\mathrm{n}=12)$ and $N \operatorname{tn} 1^{\text {lox/lox }}(\mathrm{n}=13)$ mice. $P=0.3738$ (two-sided $\mathrm{t}$ test). Data are presented as scatter and box plot, with first and third quartiles, and median. 
A

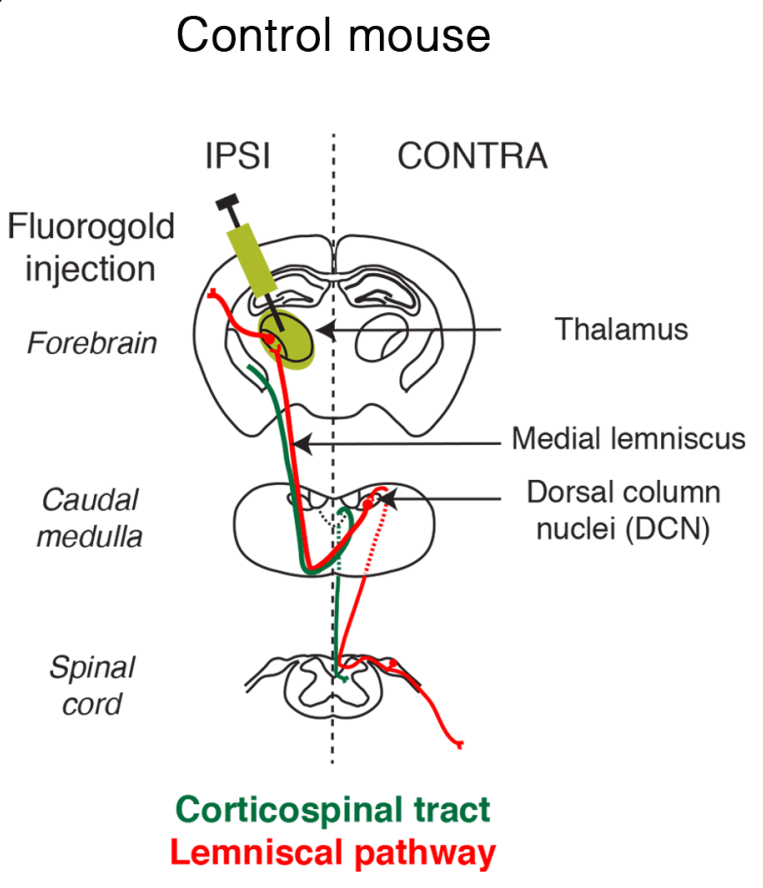

B

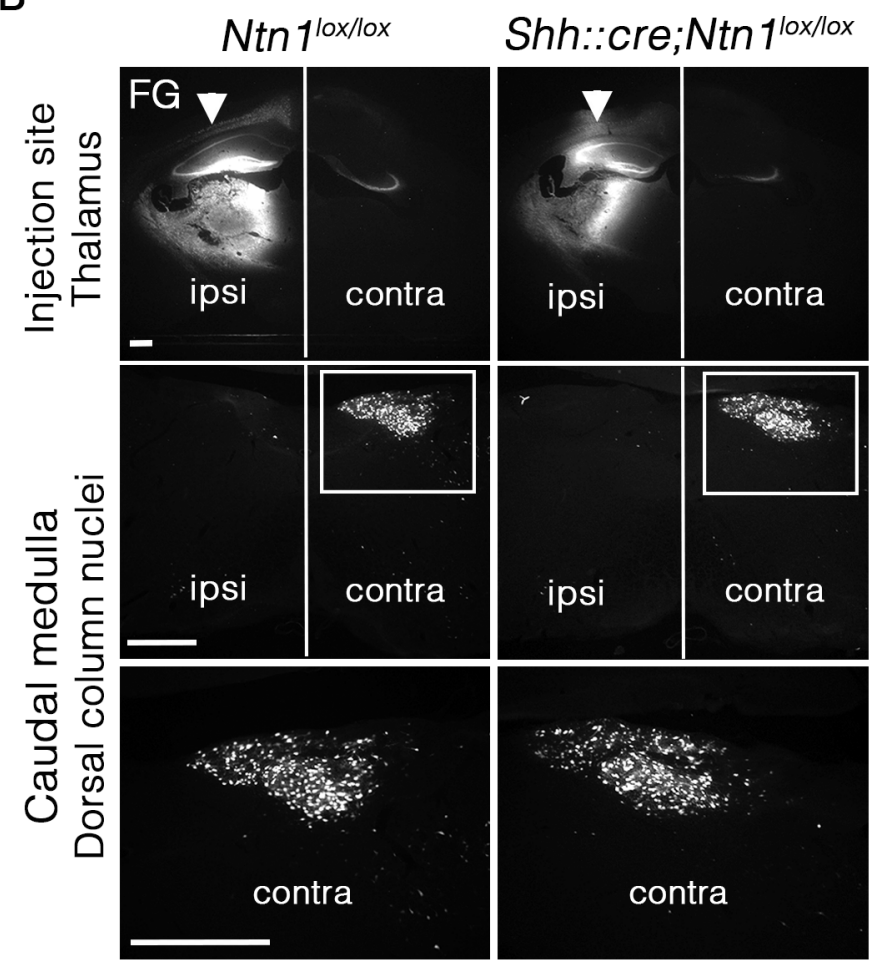


Figure S3. Neurons of dorsal column nuclei project correctly to the contralateral thalamus in Shh::cre; Ntn1 ${ }^{l o x / l o x}$ mice. Related to Figure 1

(A) Schematic showing the injection site of the retrograde tracer (yellow ellipse), the lemniscal pathway with first, second and third-order neurons (red) and the corticospinal tract (green) in an adult control mouse. (B) Top: Coronal sections of the forebrain showing the unilateral injection of FluoroGold (FG) (white arrowhead). Middle: Coronal sections of the caudal medulla where almost all FG-labeled neurons are detected in the contralateral dorsal column nuclei in both $N \operatorname{tn} 1^{\text {lox/lox }}$ and Shh::cre;Ntn1 $1^{\text {lox/lox }}$ mice. Bottom: Higher magnification of the contralateral dorsal column nuclei from the section presented above (white rectangle) where FG-labeled neurons can be visualized individually. FG, Fluorogold; ipsi and contra are respectively ipsilateral and contralateral sides with respect to the injection side; dotted line is the midline. Scale bars, $500 \mu \mathrm{m}$. 

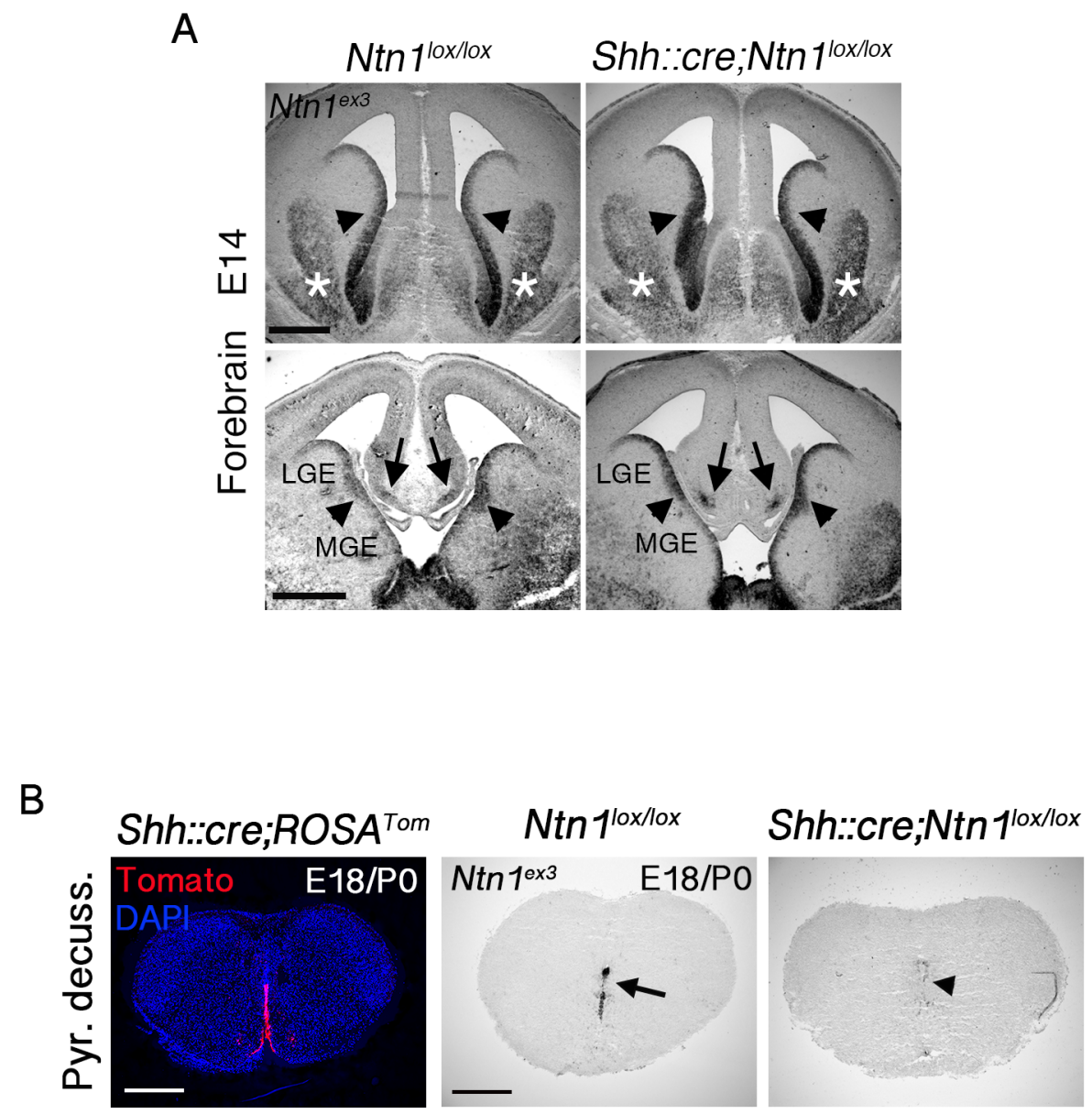
Figure S4. During development, expression of $\mathrm{Ntn} 1$ is preserved in the forebrain of Shh::cre;Ntn1 ${ }^{\text {loxllox }}$ mice, while it is removed from the floor plate of the brainstem.

\section{Related to Figure 1}

(A) Coronal sections of E14 forebrain of $N \operatorname{tn} 1^{\text {lox/lox }}(\mathrm{n}=3)$ and Shh::cre;Ntn ${ }^{\text {lox/lox }}$ mice $(\mathrm{n}=3)$ (top: rostral, bottom: caudal level). At E14, Ntn1 $m R N A$ is mostly expressed in the ventricular zone of the ganglionic eminences (arrowheads), in the ventral forebrain (white star) and in the glial wedges (arrows). This distribution is similar between Ntn $1^{\text {lox/lox }}$ and Shh::cre;Ntn1 $1^{\text {lox } / l o x}$ mice. Ntn $1^{e x 3}$, riboprobe against the exon 3 of the mouse Ntn1 $m R N A$; LGE/MGE, lateral/medial ganglionic eminence. (B) Coronal sections of E18/P0 pyramidal decussation (pyr. decuss.) of Shh::cre;ROSA ${ }^{\text {Tom }}$ (left, $\mathrm{n}=3$ ), Ntn $1^{\text {lox/lox }}$ (middle, $\mathrm{n}=2$ ) and Shh::cre;Ntn $1^{\text {lox/lox }}$ (right, $\mathrm{n}=3$ ). In Shh::cre;ROSA $A^{\text {Tom }}$, Tomato is expressed at the floor plate. At the pyramidal decussation Ntnl is only expressed at the floor plate (black arrow) in E18/P0 $N \operatorname{tn} 1^{\text {lox/lox }}$ control mice. Accordingly, no remaining Ntnl expression (black arrowhead) can be detected at the pyramidal decussation of E18/P0 Shh::cre;Ntn1 ${ }^{\text {lox/lox }}$ control mice. Scale bars, $500 \mu \mathrm{m}$. 

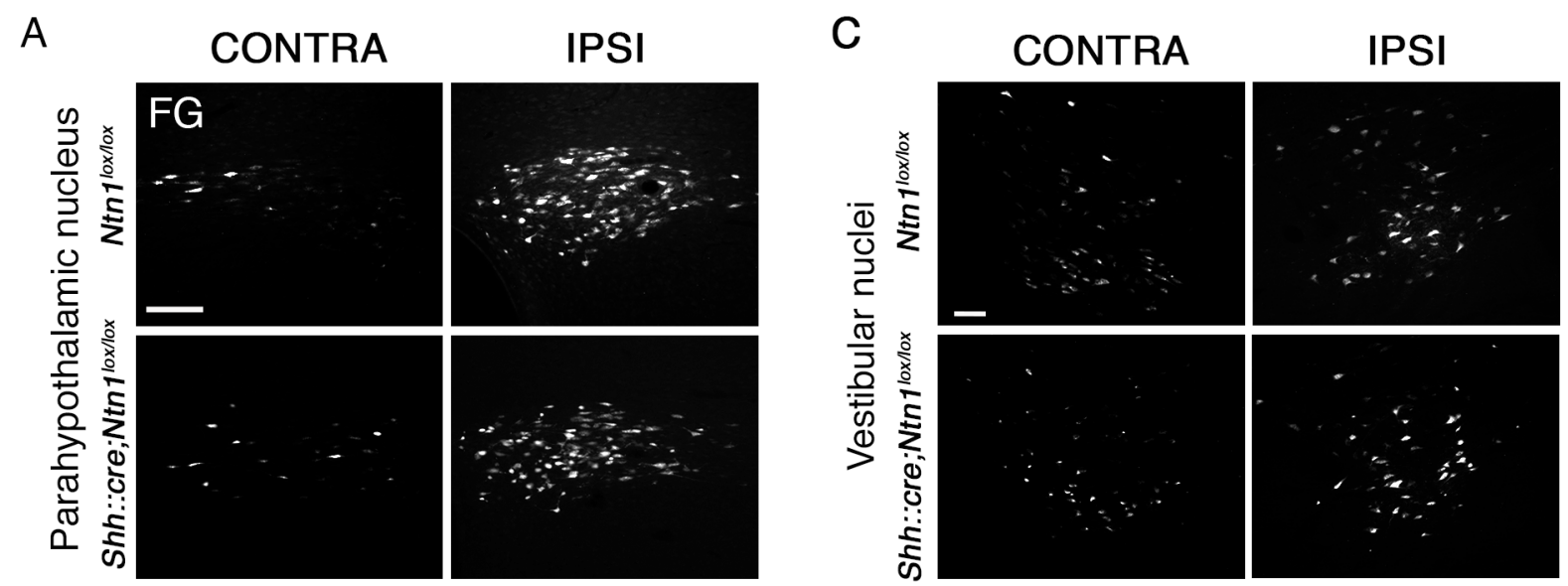

B

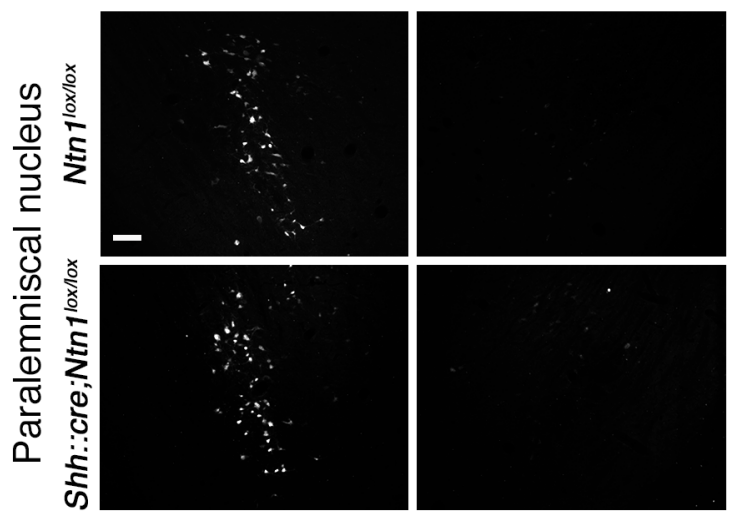

E

Parahypothalamic nucleus

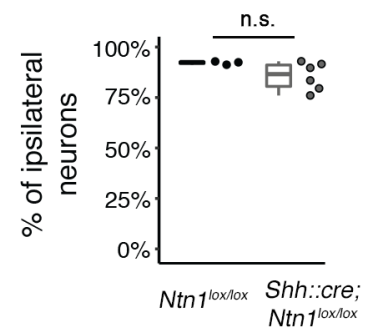

Paralemniscal nucleus

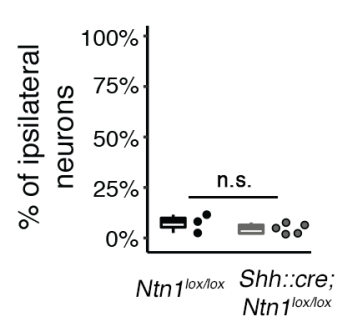

D

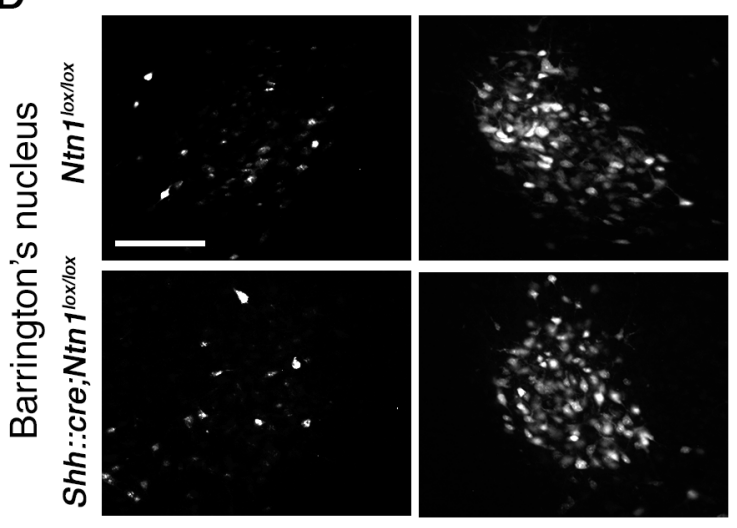

Vestibular nucleus

Barrington's nucleus
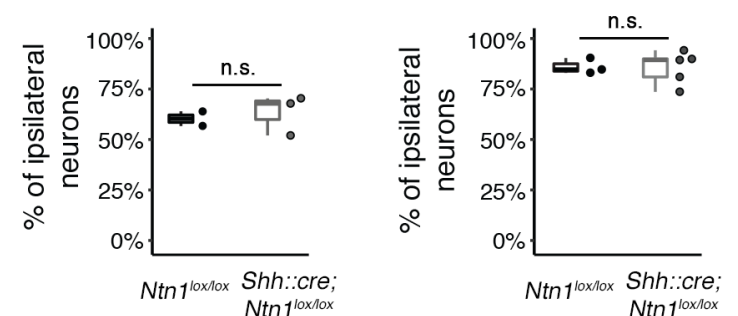
Figure S5 Lateralization of the spinal projections of parahypothalamic nucleus, paralemniscal nucleus, vestibular nuclei and Barrington's nucleus is preserved in Shh::cre; Ntn1 ${ }^{l o x / l o x}$ mice. Related to Figure 2

(A) Coronal sections of the contralateral and ipsilateral parahypothalamic nuclei of Ntn1 $1^{\text {lox/lox }}$ $(\mathrm{n}=3)$ and Shh::cre;Ntnl $1^{\text {lox/lox }}$ mice $(\mathrm{n}=6)$. FluoroGold $(\mathrm{FG})$-positive neurons are mostly detected on the ipsilateral side in both $N \operatorname{tn} 1^{\text {lox/lox }}$ and Shh::cre;Ntnl $1^{\text {lox/lox }}$ mice. (B) Coronal sections of the contralateral and ipsilateral paralemniscal nuclei of $N \operatorname{tn} 1^{\operatorname{lox} / l o x}(\mathrm{n}=3)$ and Shh::cre;Ntnl ${ }^{\text {lox/lox }}$ mice $(\mathrm{n}=5)$. Almost all FG-positive neurons are detected on the contralateral side in both $N t n 1^{l o x / l o x}$ and Shh::cre;Ntn1 $1^{\text {lox/lox }}$ mice. (C) Coronal sections of the contralateral and ipsilateral vestibular nuclei of $N \operatorname{tn} 1^{\text {lox/lox }}(\mathrm{n}=2)$ and $\operatorname{Shh}:: \operatorname{cre}$;Ntn $1^{\text {lox/lox }}$ mice $(n=3)$. FG-positive neurons are detected on both sides, with a slightly higher proportion of labeled neurons on the ipsilateral side for both $N t n 1^{\text {lox/lox }}$ and Shh::cre;Ntn1 $1^{\text {lox/lox }}$ mice. (D) Coronal sections of the contralateral and ipsilateral Barrington's nuclei of $N \operatorname{tn} 1^{\operatorname{lox} / l o x}(\mathrm{n}=3)$ and Shh::cre; Ntn $1^{\text {lox/lox }}$ mice $(\mathrm{n}=5)$. FG-positive neurons are mostly detected on the ipsilateral side for both $N t n 1^{\text {lox/lox }}$ and Shh::cre;Ntn1 $1^{\text {lox/lox }}$ mice. Ipsi and contra are respectively ipsilateral and contralateral sides with respect to the injection side. Scale bars, $100 \mu \mathrm{m}$. (E) Quantification of the lateralization of FG labeling in $N t n 1^{\text {lox/lox }}$ (black dots) and Shh::cre;Ntn1 $1^{\text {lox/lox }}$ mice (grey dots). $P_{\text {Parahypothalamic }}=0.054$ (two-sided t test) $; P_{\text {Paralateral }}=0.302$ (two-sided t test); $P_{\text {Vestibular }}$ $=0.723\left(\right.$ two-sided t test) $; P_{\text {Barrington }}=0.943$ (two-sided t test). Data are presented as scatter and box plot, with first and third quartiles, and median. 